EXPERIMENTAL SUPPORT STUDIES

FOR THE PERCOL AND

TRANSPORT MODELS

R. C. Routson and R.J. Serne

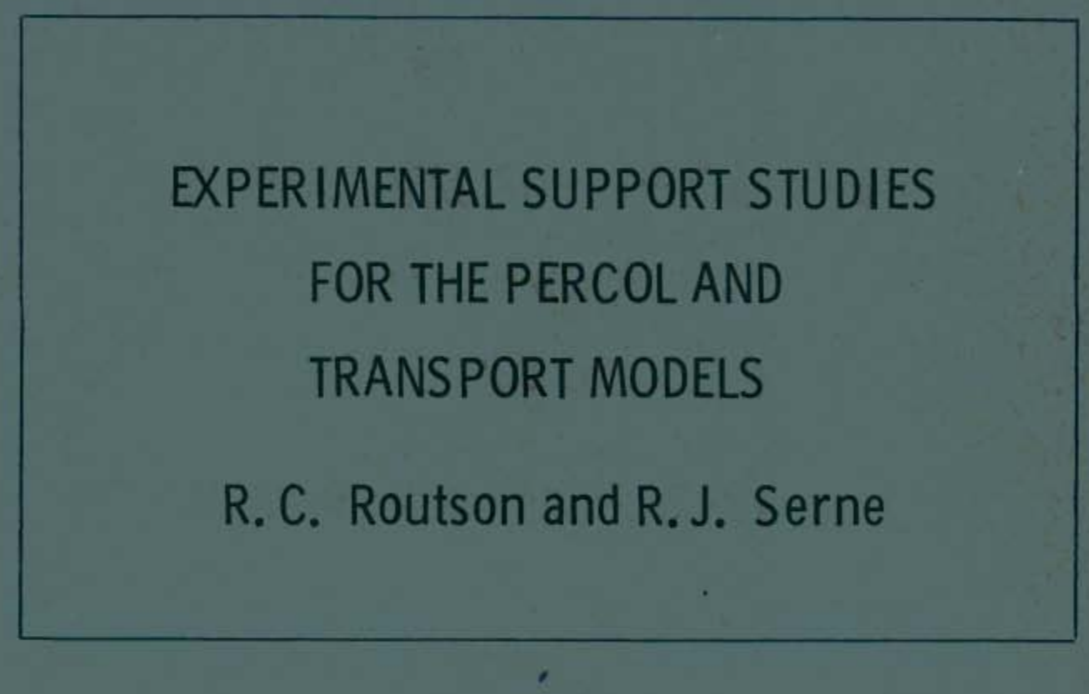

1972

Prepared for the U.S. Atomic Energy Commission under Contract AT(45-1):1830 
The report was prepared as an account of work sponsored by the United States Government. Neither the United States nor the United States Atomic Energy Cormmission, nor any of their employees, nor any of their contractors, subcontractors, or their employees, makes any warranty, express or implied, or assumes any legal liability or responsibility for the accuracy, completeness or usefulness of any information, apparatus, product or process disclosed, or represents that its use would not infringe privately owned rights.

\author{
PACIFIC NORTHWEST LABORATORY \\ operated by \\ BATTELLE \\ for the \\ U.S. ATOMIC ENERGY COMMISSION \\ Under Contract AT(45-1)-1830
}

\author{
Printed in the United States of America \\ Available from \\ National Technical Information Service \\ U.S. Department of Commerce \\ 5285 Port Royal Road \\ Springtield, Virginia 22151 \\ Price: Printed Copy \$5.45; Microtiche \$1.45
}




\section{EXPERIMENTAL SUPPORT STUDIES FOR THE PERCOL AND TRANSPORT MODELS}

by

R. C. Routson

R. J. Serne

Water and Land Resources Department

This report is based on work sponsored by the Atlantic Richfield Hanford Company under United States Atomic Energy Commission Contract (AT (45-1)-2130

BATTELLE

PACIFIC NORTHWEST LABORATORIES

RICHLAND, WASHINGTON 99352 


\section{SUMMARY}

A group of support studies conducted during development of a transport model for the Radionuclides in Soils Program is described in this report.

Measurement studies for sorption parameters concluded that: 1) small calcium experiments are more useful than batch experiments for measuring the $\mathrm{Kd}$ of trace solutes which are sorbed by ion-exchange, unless the batch system is prewashed several times with influent prior to measuring the $\mathrm{Kd}$; 2) the decrease in Kd often reported with an increasing soilto-solution ratio is the result of the reaction of the soil solid phase with the influent solution; 3) batch and small column Kds will agree if the equilibrium chemical environment is equivalent; and 4) the number of regression equations required to adequately define sorption in soil column work is a determinable function for each soil.

The sorption of Eu was found to depend upon both ion exchange and the filtration of radiocolloids formed by solution hydrolysis in the soil. Either centrifugation or filtration was capable of removing radiocolloidal Eu from solution. Formation of radiocolloidal Eu is a predictable function of $\mathrm{pH}$ and solution concentration of $\mathrm{Ca}(\mathrm{Ca})$. It is independent of the solution concentration of $\mathrm{Na}$. Multiple 
regression analysis was used to develop regression equations for predicting Eu hydrolysis as a function of equilibrium $\mathrm{pH}$ and (Ca) over $3 \mathrm{pH}$ ranges. Regression coefficients ( $r$ ) for the 3 ranges were $0.96,0.96$, and 0.54 , showing the high correlation of hydrolysis with $\mathrm{pH}$ and $(\mathrm{Ca})$. Once radiocolloidal Eu was removed by centrifugation or filtration, Kd values could be determined for the balance of the Eu.

In further study a method was developed for calculating activity coefficients for solutions with ionic strengths greater than 0.5 . This method allows extension of the PERCOL $^{1}$ model to high ionic strength solutions.

A method was developed to estimate the KdSr in Hanford groundwater as a function of the soil's transmissivity. Data from 5 wells were used to make a regression analysis. KdSr was found to be a linear function of the log of the permeability and the regression coefficient for the equation was found to be 0.799 .

Unsorbed solute was measured through soil columns using $\mathrm{Cl}^{-}$and ${ }^{3} \mathrm{H}$. The effective porosity was found to be $7.7 \pm$ 2 percent smaller than the calculated porosity. These data were also used to calculate dispersion for the soil columns. 


\section{$\underline{\text { FIGURES }}$}

$\underline{\text { Figure }}$

Page

1 Fraction Centrifuged as a Function of Time and $\mathrm{pH}$. . . . . . . . . . . . . . . 14

2 Fraction of $140 \mathrm{cpm} / \mathrm{ml}$ Eu Remaining in Solution after Centrifugation. . . . . . . . . . 15

3 Normalized Effluent Concentration (C/Co) of Cl from a $25 \mathrm{~cm}$ Tank Farm Sandy Loam Soil Column as a Function of Effluent Solution Volume . . . . . . . . . . . . . . . .

4 Normalized Effluent Concentration (C/CO) of Cl from a $25 \mathrm{~cm}$ Tank Farm Sandy Loam Soil Column as a Function of Effluent Solution Volume . . . . . . . . . . . . . . . .

5 Normalized Effluent Concentration $(\mathrm{C} / \mathrm{Co})$ of ${ }^{3} \mathrm{H}$ from a $25 \mathrm{~cm}$ Tank Farm Sandy Loam Soil Column as a Function of Effluent Solution Volume . . . . . 38

6 Normalized Effluent Concentration (C/Co) of $3 \mathrm{Cl}$ from a $25 \mathrm{~cm}$ Tank Farm Sandy LOam Soil Column as a Function of Effluent Solution Volume . . . . . .

7 Normalized Effluent Concentration (C/Co) of $\mathrm{Cl}$ from a $25 \mathrm{~cm}$ Tank Farm Sandy Loam Soil Column as a Function of Effluent Solution Volume . . . . . 
1 Batch Strontium Distribution Coefficients (KdSr) for Burbank Sand as a Function of the Soil to Solution Ratio . . . . . . . . . .

2 Batch Strontium Distribution Coefficients and Equilibrium ( $\left.\mathrm{Ca}^{++}\right)$Concentration for a Burbank Sand as a Function of Soil to Solution Ratio . . . . . . . . . . . . . . .

3 Batch Strontium Distribution Coefficients (KdSr) and Equilibrium $\left(\mathrm{Ca}^{++}\right.$) Concentration for a Burbank Sand after Four Influent Solution Washes Prior to Measurements. . . . . .

4 Equations to Predict $\mathrm{KdSr}(\mathrm{ml} / \mathrm{g})$ as a Function of Equilibrium Macroion Concentration Over the Total Ca-Concentration Range of 0.002-0.05 M for a Burbank Sand Subsoil . . . . . . . . .

5 KdSr Predicted from Regression Equations from Selected Equilibrium Macroion Values . . . . . 8

6 Europium Sorption as a Function of $\mathrm{pH}$, ( (Ca), (Na), and $\mathrm{Co}$. . . . . . . . . . . 10

7 Measured and Estimated Activity Coefficients for Pure Salt Solutions. . . . . . . . . . 17

8 Measured and Estimated Activity Coefficients for a $\mathrm{NaCl}-\mathrm{Na}_{2} \mathrm{SO}_{4}$ Solution . . . . . . . . . . . 18

9 Measured and Estimated Activity Coefficients for a $\mathrm{NaCl}_{-\mathrm{MgCl}_{2}}$ Solution. . . . . . . . . . . 18

10 Measured and Estimated Activity Coefficients for a $\mathrm{NaCl}-\mathrm{Na}_{2} \mathrm{SO}_{4}$ Solution . . . . . . . . . . . 19

11 Measured and Estimated Activity Coefficients for Mixed Salt Solutions . . . . . . . . . . 21

12 Measured and Estimated Activity Coefficients for $\mathrm{NaNO}_{3} \mathrm{KNO}_{3}$ Mixed Salt Solutions . . • . . • •

13 Empirical Interaction Constant $\left(\mathrm{B}_{\mathrm{CaSO}_{4}}\right)$ for $\mathrm{CaSO}_{4}$ as a Function of Ionic 


\section{TABLES (continued)}

Tables

$\underline{\text { Page }}$

14 Estimated Transmissivity, Hydraulic Thickness and Permeability of Selected Hanford Wells. . . . . 34

15 KdSr and Permeability for the Saturated Zone of Well 38-65Q . . . . . . . . . . 35

16 Column Parameters for a Tank Farm Sandy Loam Soil Column. . . . . . . . . . . . . 37

A-l KdSr and Permeability for the Saturated Zone of Well 32-70.. . . . . . . . . . . . A-1

A-2 KdSr and Permeability for the Saturated Zone of Well 1-18. . . . . . . . . . . . . A-2

A-3 KdSr and Permeability for the Saturated Zone of Well 3l-3lP. . . . . . . . . . . . A-3

A-4 KdSr and Permeability for the Saturated Zone of Well 37-43P . . . . . . . . . . . . . A-4

B-1 Column Parameters for a Tank Farm Sandy Loam Soil Column. . . . . . . . . . . . . B-1

B-2 Column Parameters for a Tank Farm Sandy Loan Soil Column. . . . . . . . . . . . . . B-l

B-3 Column Parameters for a Tank Farm Sandy Loam Soil Column. . . . . . . . . . . . . B-2

B-4 Column Parameters for a Tank Farm Sandy Loam Soil Column. . . . . . . . . . . . . . . B-2 
EXPERIMENTAL SUPPORT STUDIES FOR THE

PERCOL AND TRANSPORT MODELS

\section{INTRODUCTION}

The PERCOL model was developed for the Radionuclides in Soils Program to account for the significant chemical reactions which control the movement of macroions and radionuclides through multi-ion soil systems. The chemical reactions portion of the PERCOL model has been incorporated directly into the transport model to account for the soil sorption of radionuclides. Details of the PERCOL and transport models are given in $B N W L-1718^{1}$ and $B N W L-1715,{ }^{2}$ respectively.

Chemical reactions considered by the PERCOL model include ion-exchange of macroions, including $\mathrm{Na}, \mathrm{K}, \mathrm{Ca}$, and $\mathrm{Mg}$, sorption of microions, dissolution-precipitation of $\mathrm{CaCO}_{3}, \mathrm{~F}_{2}$ ' and $\mathrm{CaSO}_{4}$, complexation of $\mathrm{Ca}$ by solution $\mathrm{CaSO}_{4}$, and dissolution of soluble salts from an initially dry soil. The PERCOL model is sufficiently flexible to allow the addition of other significant chemical reactions which may in part control ion movement in soil systems.

A number of semi-independent soil-waste reaction studies were conducted in support of the PERCOL and transport models for the Radionuclides in Soils Program. These studies can be divided into three general categories: 1) verification of PERCOL model assumptions: 2) extension of the transport model to additional systems; and 3) development of methods to 
acquire data for estimating dispersion and apparent porosity. An introduction and description of each of these studies follows. 


\section{VERIFICATION OF PERCOL MODEL ASSUMPTIONS}

\section{MEASUREMENT OF THE DISTRIBUTION COEFFICIENTS}

The distribution coefficient (Kd) is the measured empirical sorption parameter used in the PERCOL model to calculate the sorption of radionuclides. It is defined as:

$$
\mathrm{Kd}=\frac{\mathrm{As} / \mathrm{W}}{\mathrm{A} 1 / \mathrm{V}}
$$

where:

$$
\begin{aligned}
\text { As }= & \text { the equilibrium concentration or activity sorbed } \\
& \text { on the solid phase } \\
\mathrm{W}= & \text { the weight of the solid phase in grams } \\
\mathrm{Al}= & \text { the equilibrium concentration or activity of the } \\
& \text { solution phase } \\
\mathrm{V}= & \text { the volume of solution in milliliters }
\end{aligned}
$$

Thus, $\mathrm{Kd}$ is the ratio of the equilibrium sorbed activity per gram ( $g$ ) of soil to the equilibrium solution activity per milliliter ( $\mathrm{ml}$ ) of solution and has the units of $\mathrm{ml} / \mathrm{g}$. Either batch or column studies can be used to measure the Kd on soils. Details of ejach of the above experimental methods are given in BNWL-1721.

The use of the distribution coefficient (Kd) as a sorption parameter in the PERCOL model requires that this parameter be measurable in a large variety of soil-water systems. While $\mathrm{Kd}$ values had been measured in essentially all of the proposed systems by either batch or small column techniques, two problems were found to cast considerable doubt on the usefulness of the obtained values. First, the distribution coefficients were found by others to be dependent upon the soil to solution ratio used in the experiment; secondly, batch and small column Kds did not generally give the same value.4,5 Therefore, methods were needed for either obtaining agreement between batch and small column kds and agreement for batch kds at differing soil to solution ratios, or for predicting data for one technique from the other.

Batch experiments using a Burbank sand were designed to 1) determine the cause of an observed decrease in the KaSr with an increasing soil to solution ratio, 2) explain the 
lower KdSr measured by a batch technique as compared to a column technique, and 3) determine which of the two techniques was better for measuring the KdSr for proposed factorial design experiments. Table 1 shows how the KdSr changes with an increasing soil to solution ratio for a $0.05 \mathrm{M}\left(\mathrm{Na}^{+}\right)$, $0.05 \mathrm{M}\left(\mathrm{K}^{+}\right), 0.002 \mathrm{M}\left(\mathrm{Ca}^{++}\right)$and $\mathrm{pH} 9.2$ influent solution. There is approximatêly a threefold increase in the KdSr with a tenfold decrease in the soil to solution ratio.

TABLE 1. BATCH STRONTIUM DISTRIBUTION COEFFICIENTS (KASr) FOR BURBANK SAND AS A FUNCTION OF THE SOIL TO SOLUTION RATIO

$\frac{\text { Soil to Solution Ratio }}{(\mathrm{g} / \mathrm{g})}$

.1

.2

.5

1.0
$\mathrm{KdSr}$ $(\overline{\mathrm{ml} / \mathrm{g}})$

3.5

2.5

1.6

1.2

The equilibrium concentration of $\left(\mathrm{Ca}^{++}\right)$was measured on duplicate batch samples; their KdSr values are listed in Table 2 .

TABLE 2. BATCH STRONTIUM DISTRIBUTION COEFFICIENTS AND EQUILIBRIUM $\left(\mathrm{Ca}^{++}\right)$CONCENTRATIONS FOR A BURBANK SAND AS A FUNCTION OF SOIL TO SOLUTION RATIO

$\frac{\text { Soil to Solution Ratio }}{(g / g)}$

$$
1
$$$$
.2
$$

.5

1.0
$\frac{\mathrm{KdSr}}{(\mathrm{ml} / \mathrm{g})}$
3.7
2.6
1.6
1.2 $\frac{\left(\mathrm{Ca}^{++}\right)}{(\mathrm{M})}$

$$
4.1 \times 10^{-3}
$$$$
7.0 \times 10^{-3}
$$

$14.0 \times 10^{-3}$

$23.0 \times 10^{-3}$ 
Good KdSr agreement was obtained between the two replicates. It can be seen that there is a fivefold increase in the equilibrium $\left(\mathrm{Ca}^{++}\right)$with a tenfold increase in the soil to solution ratio. Since the KdSr is highly dependent on the equilibrium $\left(\mathrm{Ca}^{++}\right.$) concentration, the solid phase was presumed to have reacted with the influent solution to increase the equilibrium ( $\mathrm{Ca}^{++}$) concentration. The observed increase in $\left(\mathrm{Ca}^{++}\right)$was probably due to the exchange of $\left(\mathrm{Na}^{+}\right)$and $\left(\mathrm{K}^{+}\right)$ for $\left(\mathrm{Ca}^{++}\right)$and the dissolution of Ca-salts.

To check the above suppositions a batch experiment was conducted in which all soil to solution ratios were equilibrated with the influent macroions by serially washing with the influent solution. Each soil to solution ratio was given four washes. Results are summarized in Table,3. It can be seen that pretreatment washes reduced the $\left(\mathrm{Ca}^{++}\right)$concentration to that of the influent $\left(0.002 \mathrm{M} \mathrm{Ca}^{++}\right)$for the two lowest soil to solution ratios but not for the two highest soil to solution ratios. The decrease in $\left(\mathrm{Ca}^{++}\right)$due to washing resulted in a concomitant increase in the KdSr. Ion exchange and ca-salt dissolution does appear to be the cause of the change in KdSr with changing soil to solution ratios.

TABLE 3. BATCH STRONTIUM DISTRIBUTION COEFFICIENTS (KdSr) AND EQUILIBRIUM $\left(\mathrm{Ca}^{++}\right)$CONCENTRATION FOR A BURBANK SAND AFTER FOUR INFLUENT SOLUTION WASHES

\begin{tabular}{ccc} 
Soil to Solution Ratio & $\frac{\text { KdSr}}{(\mathrm{ml} / \mathrm{g})}$ & $\frac{\left(\mathrm{Ca}^{++}\right)}{(\mathrm{eq} / 1)}$ \\
\hline .1 & 7.3 & $2.0 \times 10^{-3}$ \\
.2 & 7.8 & $1.9 \times 10^{-3}$ \\
.5 & 4.9 & $2.6 \times 10^{-3}$ \\
1.0 & 3.5 & $3.7 \times 10^{-3}$
\end{tabular}

A small column experiment using the same influent solution was conducted to compare the results with the equilibrium kds produced by the above batch techniques. The Kd measured by the small column technique was 7.6 , a good agreement with the equilibrium batch Kd. 
This study indicates that

- small column experiments are more useful than batch experiments unless the soil is prewashed several times with the influent solution prior to measuring the Kdsr;

- the decrease in the KdSr with an increasing soil to solution ratio is the result of the reaction of the soil solid phase with the influent solution; and

- batch and small column Kds will agree if the equilibrium chemical environments of the two systems are equivalent.

\section{ESTIMATION OF THE NUMBER OF LINEAR SORPTION EQUATIONS}

In the PERCOL and transport models the radionuclide sorption is determined empirically as a function of the soil type, macroion equilibrium concentrations and $\mathrm{pH}$ of the solution. statistical two-level factorial design experiments are conducted to obtain the Kd predictor equations. Over order of magnitude solution concentration ranges of macroions the effect of macroion concentration on the Kd cannot be expected to be linear. This is especially true for a Kd which is sensitive to the solution concentration of a macroion (such as the $\mathrm{Kd}$ of strontium, which is affected by the solution concentration of calcium). 5 In such cases, when more than a single empirically derived equation is necessary to adequately predict the sorption of a trace radionuclide in a soil-water system, a method is required to determine the number of equations needed. Following is the description of a method which has been used for this purpose.

From preliminary factorial design experiments the sorption of strontium was found to be most sepsitive to the macroion concentration of $\left(\mathrm{Ca}^{++}\right)$in solution. ${ }^{5}$ By subdividing the $\mathrm{Ca}$ concentration range of this sensitive independent variable much better agreement can be obtained between the observed and predicted Kds; uncertainties in the effects of the more sensitive variables are reduced and interaction terms may become insignificant, simplifying the empirical equations. Frequently the equations become nearly linear.

The Kd of radioactive $\mathrm{Sr}$ was measured in small columns on a Burbank sand subsoil to determine the number of empirical sorption equations required to satisfactorily predict the KdSr as a function of solution macroion concentration over a specified solution $\left(\mathrm{Ca}^{++}\right)$concentration range. Statistical 
two-level factorial design experiments were conducted in which KdSr measurements in small columns were used to derive equations for intermediate KdSr prediction. The Ca-concentration range of 0.002-0.05 $\mathrm{M}$ was divided into one, two and three subranges and an equation was derived for the KdSr over ${ }_{3}$ each subrange. Experimental details are listed in BNWL-1721.3

Table 4 gives the derived sorption equations and the macroion concentration range for which each equation is valid. $\mathrm{K}, \mathrm{Na}$, and $\mathrm{pH}$ concentration ranges were 0.0 and $0.05 \mathrm{M}, 0.02$ and $0.2 \mathrm{M}$ and 7.0 , respectively.

TABLE 4. EQUATIONS TO PREDICT $\mathrm{kdSr}$ (m $\mathrm{l} / \mathrm{g}$ ) AS A FUNCTION OF EQUILIBRIUM MACROION CONCENTRATIONS OVER THE TOTAL Ca CONCENTRATION RANGE OF 0.002-0.05 M FOR A BURBANK SAND SUBSOIL

\begin{tabular}{|c|c|c|}
\hline $\begin{array}{l}\text { Subrange } \\
\text { Number }\end{array}$ & $\begin{array}{c}\mathrm{Ca} \text { range } \\
-\mathrm{M}- \\
\end{array}$ & Regression Equation \\
\hline 1 & $0.0020-0.050$ & $\begin{aligned} \mathrm{KdSr}= & 3.46-2.83 \mathrm{X} \mathrm{Cal}^{1}-1.62 \mathrm{XK}^{2} \\
& +1.45 \mathrm{XKXCal}-1.35 \mathrm{XNa}^{3} \\
& +1.24 \times \mathrm{XNaXCal}+1.00 \mathrm{XNaXK} \\
& -0.97 \mathrm{XNaXCal} \times \mathrm{XK}\end{aligned}$ \\
\hline $2 a$ & $0.0020-0.0035$ & $\begin{aligned} \mathrm{KdSr}= & 5.29-1.04 \mathrm{XCa} 2 \mathrm{a}^{4}-2.59 \mathrm{XK}+0.49 \\
& \text { XKXCa2a-2.11XNa+0.51XNaXCa} 2 \mathrm{a} \\
& +1.56 \mathrm{XNaXK}-0.41 \mathrm{XNaXKXCa2a}\end{aligned}$ \\
\hline $2 \mathrm{~b}$ & $0.0035-0.050$ & $\begin{aligned} \mathrm{KdSr}= & 2.64-2.10 \mathrm{XCa} 2 \mathrm{~b}^{5}-1.22 \mathrm{XK}+1.05 \\
& \text { XKXCa } 2 \mathrm{~b}-0.62 \mathrm{XNa}+0.61 \times \mathrm{XNaXCa} 2 \mathrm{~b} \\
& +0.50 \mathrm{XNaXK}-0.47 \mathrm{XNaXKXCa} 2 \mathrm{~b}\end{aligned}$ \\
\hline $3 a$ & $0.0020-0.0035$ & $\mathrm{KdSr}=$ Same as $2 \mathrm{a}$ \\
\hline $3 b$ & $0.0035-0.0050$ & $\begin{aligned} \mathrm{KdSr}= & 4.31-0.62 \times \mathrm{Xa} 3 \mathrm{~b}+0.062 \mathrm{XCa} 3 \mathrm{bXK} \\
& -1.70 \times \mathrm{xK}-1.41 \mathrm{XNa}+0.92 \mathrm{XNaX} \\
& -0.062 \mathrm{XKXCa} 3 \mathrm{bNa}\end{aligned}$ \\
\hline $3 c$ & $0.0050-0.050$ & 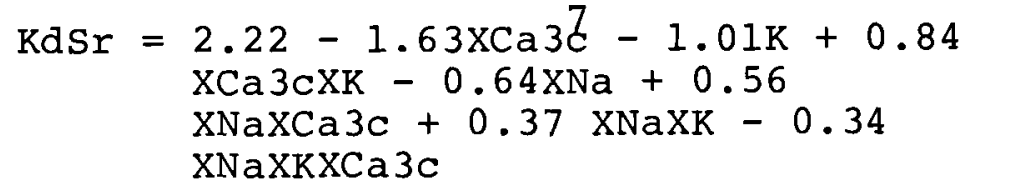 \\
\hline
\end{tabular}

Notes:

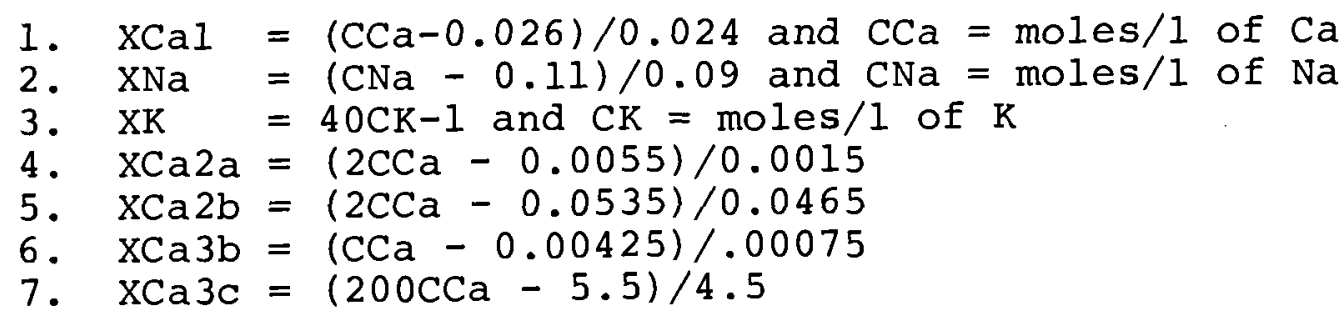


Table 5 lists selected sample calculations from equations $1,2 a, 2 b, 3 a, 3 b$, and $3 c$ of the KdSr for some chosen macroion concentrations. $\mathrm{K}, \mathrm{Na}$ and $\mathrm{pH}$ were held constant at $0.025 \underline{M}, 0.1 \underline{M}$, and 7.0 , respectively.

TABLE 5. KdSr PREDICTED FROM REGRESSION EQUATIONS FROM SELECTED EQUILIBRIUM MACROION VALUES

\begin{tabular}{ccc} 
Subrange Number & $\begin{array}{c}\text { Ca-Macroion Concentration } \\
-\mathrm{M}-\end{array}$ & $\begin{array}{c}\mathrm{Kd} \\
-\mathrm{m} \ell / \mathrm{g}-\end{array}$ \\
\cline { 2 - 3 } 1 & 0.003 & 6.5 \\
$2 \mathrm{a}$ & 0.003 & 5.2 \\
$3 \mathrm{a}$ & 0.003 & 5.2 \\
1 & 0.004 & 6.4 \\
$2 \mathrm{~b}$ & 0.004 & 4.7 \\
$3 \mathrm{~b}$ & 0.004 & 4.8 \\
1 & 0.01 & 3.9 \\
$2 \mathrm{c}$ & 0.01 & 3.8 \\
$3 \mathrm{c}$ & 0.01 & 3.7
\end{tabular}

It can be seen that a subdivision of two or three regression equations essentially predicts the same KdSrs, suggesting that the single equation may predict a high KdSr at a low Caconcentration (however, agreement is within experimental error at a high solution Ca-concentration). In addition, it appears that two regression equations are sufficient to predict the KdSr since no advantage is obtained by dividing the Ca range into three parts.

To further check the adequacy of subdividing by two instead of three, both sets of equations were used as input to the computer sorption model PERCOL to predict the movement of ${ }^{85} \mathrm{Sr}$ through a soil column. Both sets of equations gave essentially the same results. Furthermore, in a related experiment both predicted ${ }^{85} \mathrm{Sr}$ movements through the column agreed within 2 percent up to a normalized ${ }^{85} \mathrm{Sr}$ movement of $0.85(\mathrm{C} / \mathrm{CO})$. 
STUDIES TO EXTEND THE TRANSPORT MODEL

\section{SORPTION OF RARE EARTH RADIONUCLIDES}

Rare earth and actinide radionuclides are sorbed by both ion exchange and precipitation reactions. ${ }^{6}$ Use of a kd to characterize a sorption reaction assumes that ion exchange is the primary sopption controlling the removal of a radionuclide from solution. Thus, extension of the transport model to rare earth and actinide radionuclides which may be sorbed primarily by reactions other than ion exchange requires laboratory techniques for measuring sorption in these systems as a function of solution parameters. The following group of studies was conducted to obtain this capability. Because of its commercial availability and emission of a readily counted gamma radiation, Europium (Eu) was selected for this group of experiments. Since the ground disposal of large volumes of acid wastes have resulted in the lowering of the soil pH of some portions of the Hanford Reservation, the sorption of lanthanide and actinide radionuclides (such as Eu) that were present in these wastes must be measured in acid soil systems which were initially neutral or slightly alkąline. Details of these experiments are given in BNWL-1721.3

In a preliminary small column experiment the sorption of Eu was found to be nearly 100 percent, even after 200 column volumes of $\mathrm{pH} 6.0$ solution had been passed through the soil. Thus, batch systems were investigated for the initial sorption of Eu.

Adjustment of soil pH in batch systems to lower than natural values requires large amounts of acid and the $\mathrm{pH}$ tends to initially drift upward as acid in the system reacts with the soil. Sorption of $\mathrm{Eu}$ is measurable, however, if the solid phase is separated from the liquid phase by centrifugation, thereby greatly reducing the reaction. The sorption of Eu in suspension was found to be reproducible and thus rapid in relation to the rate at which the soil pH was changing.

Batch experiments were conducted to determine the sorption of $\mathrm{Eu}$ on a tank farm sandy loam soil which had been pretreated with acid to obtain low $\mathrm{pH}$ values. Sorption was determined as a function of macroion concentration, $\mathrm{pH}$, and Eu spike concentration. Fractional sorption (C/Co) was found to be constant over a difference in Eu spike concentration of nearly an order of magnitude (Table 6). Sorption was found to be independent of $\left(\mathrm{Na}^{+}\right)$concentration, slightly dependent on $\left(\mathrm{Ca}^{++}\right)$concentration, and highly dependent upon 
TABLE 6. EUROPIUM SORPTION AS A FUNCTION OF $\mathrm{pH},(\mathrm{Ca}),(\mathrm{Na})$, AND CO

\begin{tabular}{|c|c|c|c|c|c|}
\hline $\begin{array}{l}\text { Sample } \\
\text { Number }\end{array}$ & $\mathrm{C} / \mathrm{Co}$ & $\mathrm{pH}$ & $\begin{array}{l}\mathrm{Ca} \\
(11)\end{array}$ & $\begin{array}{l}\mathrm{Na} \\
(\mathrm{M})\end{array}$ & $\begin{array}{c}\mathrm{C}_{0} \\
(\mathrm{cpm} / \mathrm{ml})\end{array}$ \\
\hline 1 & .2783 & 1.855 & .0075 & .0075 & 20500 \\
\hline 2 & .2708 & 2.00 & .0075 & .0075 & 20500 \\
\hline 3 & .2796 & 2.1 & .0075 & .0075 & 3000 \\
\hline 4 & .2916 & 2.1 & .0075 & .0075 & 3000 \\
\hline 5 & .2962 & 2.145 & .0075 & .0075 & 3000 \\
\hline 6 & .2991 & 2.175 & .0075 & .0075 & 3000 \\
\hline 7 & .2099 & 2.33 & .0075 & .075 & 3000 \\
\hline 8 & .1964 & 2.58 & .0075 & .0075 & 20500 \\
\hline 9 & .1726 & 2.585 & .0075 & .075 & 3000 \\
\hline 10 & .1391 & 2.605 & .0075 & .075 & 20000 \\
\hline 11 & .1648 & 2.725 & .0075 & .075 & 3000 \\
\hline 12 & .1480 & 2.80 & .0075 & .075 & 20000 \\
\hline 13 & .259 & 3.040 & .075 & .0075 & 16000 \\
\hline 14 & .1520 & 3.14 & .0075 & .0075 & 20500 \\
\hline 15 & .1325 & 3.165 & .0075 & .0075 & 3000 \\
\hline 16 & .1478 & 3.165 & .0075 & .0075 & 3000 \\
\hline 17 & .297 & 3.185 & .075 & .075 & 4000 \\
\hline 18 & .1157 & 3.34 & .0075 & .075 & 3000 \\
\hline 19 & .262 & 3.40 & .075 & .075 & 17000 \\
\hline 20 & .196 & 3.5 & .075 & .0075 & 16000 \\
\hline 21 & .179 & 3.655 & .075 & .075 & 4000 \\
\hline 22 & .216 & 3.67 & .075 & .075 & 4000 \\
\hline 23 & .1055 & 3.685 & .0075 & .075 & 3000 \\
\hline 24 & .174 & 3.715 & .075 & .0075 & 4000 \\
\hline 25 & .181 & 3.775 & .075 & .0075 & 4000 \\
\hline 26 & .166 & 3.80 & .075 & .0075 & 4000 \\
\hline 27 & .0933 & 3.805 & .0075 & .0075 & 3000 \\
\hline 28 & .161 & 3.83 & .075 & .075 & 4000 \\
\hline 29 & .0664 & 3.86 & .0075 & .0075 & 20500 \\
\hline 30 & .196 & 3.905 & .075 & .075 & 17000 \\
\hline 31 & .0459 & 3.95 & .0075 & .075 & 3000 \\
\hline 32 & .0366 & 4.080 & .0075 & .075 & 20000 \\
\hline 33 & .0497 & 4.1 & .0075 & .075 & 3000 \\
\hline 34 & .121 & 4.15 & .075 & .0075 & 4000 \\
\hline 35 & .0447 & 4.23 & .0075 & .0075 & 20500 \\
\hline 36 & .0354 & 4.28 & .0075 & .0075 & 3000 \\
\hline 37 & .0461 & 4.28 & .0075 & .0075 & 3000 \\
\hline 38 & .096 & 4.29 & .075 & .075 & 4000 \\
\hline 39 & .0751 & 4.365 & .075 & .0075 & 16000 \\
\hline 40 & .0918 & 4.42 & .075 & .075 & 4000 \\
\hline 41 & .087 & 4.425 & .075 & .075 & 4000 \\
\hline 42 & .0481 & 4.43 & .0075 & .075 & 3000 \\
\hline 43 & .0331 & 4.43 & .0075 & .075 & 20000 \\
\hline 44 & .080 & 4.485 & .075 & .075 & 17000 \\
\hline 45 & .0258 & 4.620 & .0075 & .0075 & 3000 \\
\hline
\end{tabular}


TABLE 6 (continued)

\begin{tabular}{|c|c|c|c|c|c|}
\hline $\begin{array}{l}\text { Sample } \\
\text { Number }\end{array}$ & ${ }^{\mathrm{C}} / \mathrm{Co}$ & $\mathrm{pH}$ & $\begin{array}{l}\mathrm{Ca} \\
(\mathrm{M})\end{array}$ & $\begin{array}{l}\mathrm{Na} \\
(\mathrm{M})\end{array}$ & $\begin{array}{c}\mathrm{C}_{\mathrm{O}} \\
(\mathrm{cpm} / \mathrm{ml})\end{array}$ \\
\hline 46 & .0238 & 4.70 & .0075 & .0075 & 3000 \\
\hline 47 & .0516 & 4.70 & .075 & .075 & 4000 \\
\hline 48 & .0157 & 4.74 & .0075 & .0075 & 20500 \\
\hline 49 & .041 & 4.785 & .075 & .0075 & 4000 \\
\hline 50 & .0237 & 4.80 & .0075 & .075 & 3000 \\
\hline 51 & .041 & 4.810 & .075 & .0075 & 16000 \\
\hline 52 & .039 & 4.84 & .075 & .0075 & 4000 \\
\hline 53 & .050 & 4.855 & .075 & .075 & 17000 \\
\hline 54 & .041 & 4.855 & .075 & .0075 & 4000 \\
\hline 55 & .0113 & 4.90 & .0075 & .075 & 20000 \\
\hline 56 & .0066 & 4.925 & .0075 & .075 & 3000 \\
\hline 57 & .0389 & 4.99 & .075 & .0075 & 4000 \\
\hline 58 & .0092 & 5.06 & .0075 & .0075 & 20500 \\
\hline 59 & .0141 & 5.07 & .0075 & .075 & 3000 \\
\hline 60 & .021 & 5.08 & .075 & .0075 & 4000 \\
\hline 61 & .0237 & 5.08 & .075 & .0075 & 16000 \\
\hline 62 & .019 & 5.175 & .075 & .0075 & 4000 \\
\hline 63 & .0131 & 5.20 & .0075 & .075 & 3000 \\
\hline 64 & .0088 & 5.20 & .0075 & .075 & 20000 \\
\hline 65 & .019 & 5.24 & .075 & .075 & 4000 \\
\hline 66 & .0032 & 5.32 & .0075 & .075 & 3000 \\
\hline 67 & .015 & 5.33 & .075 & .075 & 17000 \\
\hline 68 & .015 & 5.33 & .075 & .075 & 4000 \\
\hline 69 & .012 & 5. 355 & .075 & .0075 & 16000 \\
\hline 70 & .01226 & 5.45 & .075 & .075 & 4000 \\
\hline 71 & .0024 & 5.465 & .0075 & .075 & 3000 \\
\hline 72 & .008 & 5.555 & .075 & .075 & 17000 \\
\hline 73 & .0024 & 5.615 & .0075 & .075 & 3000 \\
\hline 74 & .0097 & 5.62 & .075 & .0075 & 4000 \\
\hline 75 & .0097 & 5.62 & .075 & .075 & 4000 \\
\hline 76 & .0011 & 5.70 & .0075 & .075 & 3000 \\
\hline 77 & .0023 & 5.70 & .0075 & .075 & 20000 \\
\hline 78 & .000 & 5.725 & .0075 & .075 & 3000 \\
\hline 79 & .0025 & 5.725 & .0075 & .075 & 20000 \\
\hline 80 & .0044 & 5.745 & .075 & .0075 & 4000 \\
\hline 81 & .0011 & 5.78 & .0075 & .0075 & 20500 \\
\hline 82 & .000 & 5.78 & .0075 & .0075 & 3000 \\
\hline 83 & .000 & 5.78 & .0075 & .0075 & 3000 \\
\hline 84 & .0008 & 5.82 & .0075 & .0075 & 20500 \\
\hline 85 & .0002 & 5.90 & .0075 & .0075 & 3000 \\
\hline 86 & .0020 & 5.90 & .0075 & .0075 & 3000 \\
\hline 87 & .006 & 6.02 & .075 & .075 & 4000 \\
\hline 88 & .0017 & 6.04 & .075 & .0075 & 16000 \\
\hline 89 & .004 & 6.082 & .075 & .0075 & 4000 \\
\hline 90 & .0021 & 6.10 & .075 & .075 & 4000 \\
\hline
\end{tabular}


TABLE 6 (continued)

\begin{tabular}{|c|c|c|c|c|c|}
\hline $\begin{array}{l}\text { Sample } \\
\text { Number }\end{array}$ & $\mathrm{C} / \mathrm{Co}$ & $\mathrm{pH}$ & $\begin{array}{l}\mathrm{Ca} \\
(\mathrm{M})\end{array}$ & $\begin{array}{l}\mathrm{Na} \\
(\mathrm{M}) \\
\end{array}$ & $\begin{array}{c}\mathrm{C}_{\mathrm{O}} \\
(\mathrm{cpm} / \mathrm{ml})\end{array}$ \\
\hline 91 & .0009 & 6.10 & .075 & .075 & 17000 \\
\hline 92 & .0015 & 6.145 & .075 & .0075 & 16000 \\
\hline 93 & .0024 & 6.155 & .075 & .0075 & 4000 \\
\hline 94 & .000 & 6.18 & .0075 & .075 & 3000 \\
\hline 95 & .0031 & 6.23 & .075 & .075 & 4000 \\
\hline 96 & .0015 & 6.240 & .075 & .075 & 17000 \\
\hline 97 & .0019 & 6.275 & .075 & .0075 & 4000 \\
\hline 98 & .00086 & 6.30 & .0075 & .075 & 20000 \\
\hline 99 & .0005 & 6.34 & .0075 & .075 & 20000 \\
\hline 100 & .0006 & 6.34 & .0075 & .075 & 3000 \\
\hline 101 & .0005 & 6.36 & .075 & .075 & 4000 \\
\hline 102 & .0027 & 6.370 & .075 & .0075 & 4000 \\
\hline 103 & .0007 & 6.43 & .0075 & .075 & 3000 \\
\hline 104 & .0015 & 6.43 & .075 & .075 & 4000 \\
\hline 105 & .000 & 6.432 & .0075 & .075 & 3000 \\
\hline 106 & .0018 & 6.44 & .075 & .0075 & 16000 \\
\hline 107 & .0008 & 6.49 & .075 & .0075 & 16000 \\
\hline 108 & .003 & 6.50 & .075 & .0075 & 4000 \\
\hline 109 & .0007 & 6.51 & .075 & .075 & 17000 \\
\hline 110 & .0019 & 6.51 & .075 & .075 & 4000 \\
\hline 111 & .0006 & 6.555 & .075 & .075 & 17000 \\
\hline 112 & .005 & 6.57 & .075 & .075 & 4000 \\
\hline 113 & .002 & 6.540 & .075 & .0075 & 4000 \\
\hline 114 & .00032 & 6.60 & .075 & .0075 & 4000 \\
\hline 115 & .0025 & 6.62 & .075 & .075 & 4000 \\
\hline 116 & .0011 & 6.680 & .075 & .0075 & 4000 \\
\hline
\end{tabular}

the $\mathrm{pH}$ of the system at values below 6.5. Above a pH of 6.5 sorption was found to be essentially 100 percent for all solutions (Table 6).

Multiple regression analysis was conducted with the data to quantitatively describe the initial sorption of $\mathrm{Eu}$ as a function of $\left(\mathrm{Ca}^{++}\right)$concentration and $\mathrm{pH} .{ }^{3}$ Regression equations were found to best fit the data when subdivided into pH ranges of $<4.7,4.7-6.0$, and 6.0-6.5. The regression equations and the multiple correlation coefficients for these respective ranges are: 
$\underline{\mathrm{pH}} \leq \mathbf{4 . 7}$

$$
\begin{aligned}
\mathrm{C} / \mathrm{Co} & =0.430-0.0934 \mathrm{pH}+3.99 \mathrm{C}_{\mathrm{Ca}}-0.697 \mathrm{pH} \mathrm{C}_{\mathrm{Ca}} \\
r & =0.96
\end{aligned}
$$

$4.7 \leq \mathrm{pH} \leq 6.0$

$\mathrm{C} / \mathrm{Co}=0.0669-0.0114 \mathrm{pH}+2.43 \mathrm{C}_{\mathrm{Ca}}-0.426 \mathrm{pH} \mathrm{C}_{\mathrm{Ca}}$

$r=0.96$

$6.0 \leq \mathrm{pH}$

$$
\begin{aligned}
\mathrm{C} / \mathrm{Co} & =0.0071+0.00116 \mathrm{pH}+0.2997 \mathrm{C}_{\mathrm{Ca}}-0.0434 \mathrm{pH} \mathrm{C}_{\mathrm{Ca}} \\
\mathrm{r} & =0.54
\end{aligned}
$$

where

$$
\begin{aligned}
\mathrm{C} / \mathrm{Co}= & \text { equilibrium solution activity of Eu divided by } \\
& \text { the influent solution activity and } \\
\mathrm{C}_{\mathrm{Ca}}= & \text { equilibrium solution concentration of } \mathrm{Ca} \text { in moles/l. }
\end{aligned}
$$

From the correlation coefficients from Equations 2 and 3 it can be seen that Eu sorption is highly correlated with the solution and equilibrium concentration of $\mathrm{Ca}^{++}$. The lower correlation coefficient of Equation 4 is probably due in part to the counting statistics at $\mathrm{pH}$ values above 6.0 , where only small Eu activities remain in solution. Equations 2 and 3 represent sorption of $\mathrm{Eu}$ due to both ion exchange and filtration of radiocolloidal Eu and thus are valid only for the initial contact with this soil. Since small column studies have shown that essentially all of the radiocolloidal Eu will be filtered by the soil and that Equations 3 and 4 will predict this, it is necessary experimentally to separate the colloidal Eu from the soluble Eu to determine Eu sorption in noncolloidal systems. Further experiments were required to measure soluble Eu sorption in other segments of the soil.

To measure the removal of the soluble Eu in the absence of $a$ soil it is first necessary to find a means of separating radiocolloidal Eu from soluble Eu. To accomplish this, a batch experiment was designed to determine the effect of $\mathrm{pH}$ on the susceptibility of radiocolloidal Eu to contrifugation from solution. Results are shown in Figure 1, where solution is $0.07 \mathrm{M} \mathrm{Ca}{ }^{++}$and Eu activity is $2200 \mathrm{cpm} / \mathrm{ml}$. It can be seen that at $\overline{\mathrm{pH}}$ values of 4.0-4.5 no Eu can be removed. At $\mathrm{pH}$ values greater than 4.5 significant amounts of Eu can be 


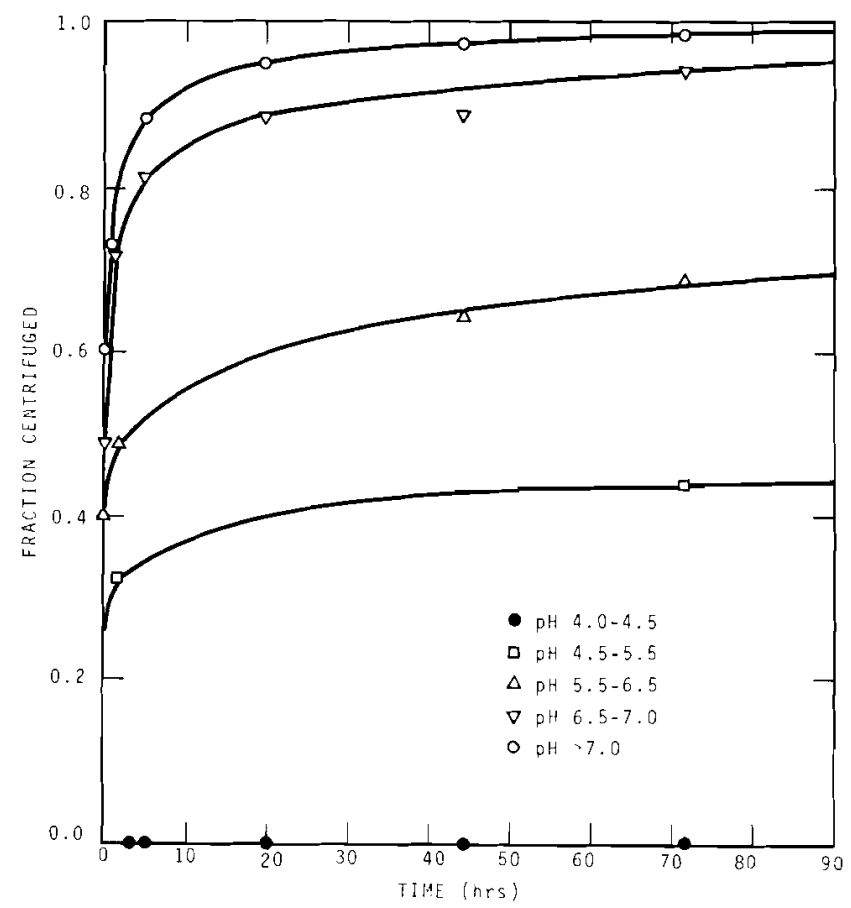

FIGURE 1. Fraction Centrifuged as a Function of Time and pH

removed and the process is both time and $\mathrm{pH}$ dependent. The higher the $\mathrm{pH}$ and the greater the time, the more Eu will be removed by centrifugation. The time dependence is probably due to a lack of surfaces for nucleation. At $\mathrm{pH}$ values above 7.0 essentially 100 percent sorption can be expected. To determine whether filtration would result in an equivalent removal, some of the above solutions were resuspended and filtered through $0.45 \mu$ filters, which are commonly used in sediment work to separate "soluble" from unsoluble components. This technique also removed radiocolloidal Eu.

In another small column experiment, a solution with an Eu activity less than the equilibrium $\mathrm{C} / \mathrm{Co}$ predicted by Equations 2,3 , and $4(140 \mathrm{cpm} / \mathrm{ml})$ was centrifuged and sorption measured as a function of $\mathrm{pH}$ to determine the sorption noncolloidal Eu. The solution was $0.07 \mathrm{M} \mathrm{Na}^{+}$and $0.007 \mathrm{M} \mathrm{Ca}{ }^{++}$. Results are shown in Figure 2. It can be seen that at $\mathrm{pH}$ values of less than 6.0 nearly 100 percent of the Eu remains in solution. Thus, distribution coefficients can be accurately determined with this solution below $\mathrm{pH} 6.0$. The above solution was percolated through small columns of a tank farm sandy loam soil at $\mathrm{pH}$ values of $4.0,4.5$, and 5.1 . The solutions were 


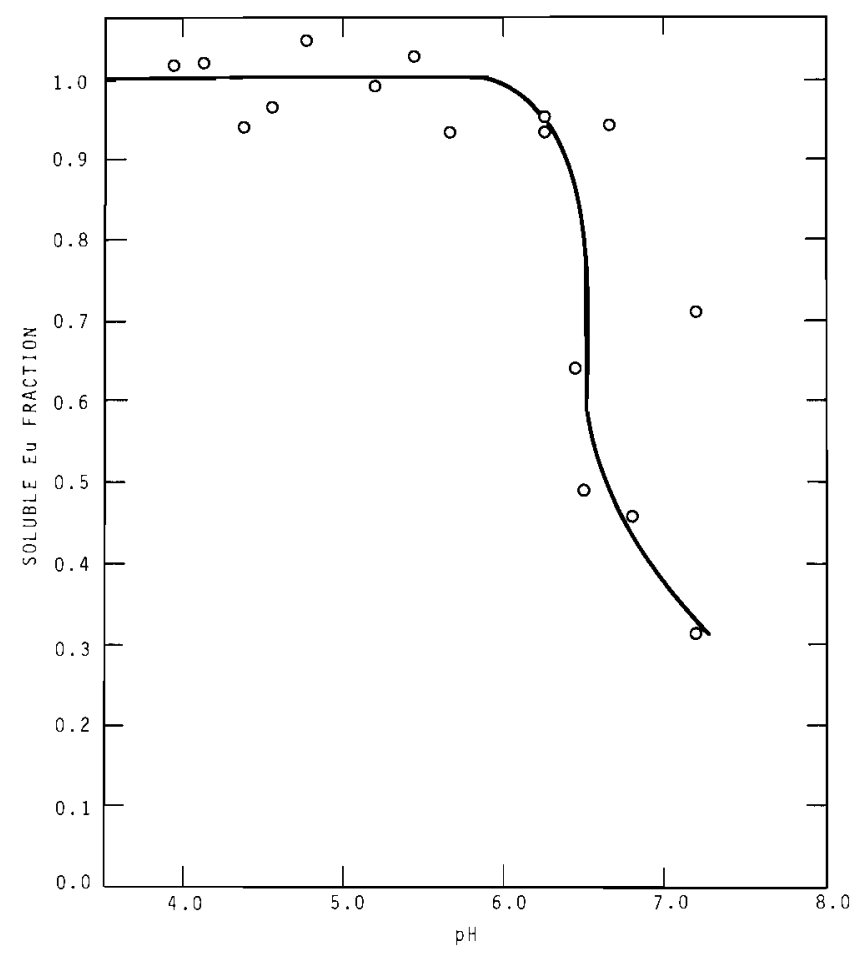

FIGURE 2. Fraction of $140 \mathrm{cpm} / \mathrm{ml}$ Eu Remaining in Solution After Centrifugation (13,000 RPM for 15 minutes)

found to attain the activity of the influent solution after $250 \mathrm{ml}$ of solution had passed through them, demonstrating that equilibrium was attained. KdEu values were 55, 106, and 521 at $\mathrm{pH}$ values of $4,4.5$, and 5.1 , respectively. Thus, Eu sorption in the first increment of soil can be predicted using Equations 2, 3, and 4. Sorption of $\mathrm{Eu}$ in all subsequent segments of soil will be by exchange processes and can be predicted from KdEu, which can be measured with either filtered or centrifuged solutions.

\section{HIGH IONIC STRENGTH ACTIVITY COEFFICIENTS}

The original PERCOL computer model used an extension of the Debye-Huckel theory to calculate the activity coefficients needed to convert the concentration data to activity data. Activity data are needed to solve the chemical equilibrium relationships that occur as wastes percolate through the soil. The theory and equations utilized in PERCOL are described in BNWL-1718. ${ }^{2}$ The original model, which utilizes Davies' extension of the Debye-Huckel equation, could calculate activity coefficients of solutions up to a maximum ionic 
strength of $0.5 \mathrm{~m}$. Above this concentration the true activity coefficients would not follow the empirical equation. Since Hanford wastes often reach ionic strengths of 3.0 to $11.0 \mathrm{~m}$ refinements to the model were warranted.

The literature on activity coefficients was reviewed and an empirical approach based on Guggenheim's adaptation of Bronsted's specific ion interaction theory was adopted.7 This approach was chosen because it matched observed data for salt solutions to ionic strengths above $5 \mathrm{~m}$ and could be readily extended to mixed salt solutions. Two principals inherent in this approach are:

1. Specific short-range interactions exist between ions of unlike charge but not between ions of like charge (Bronsted's specific ion interaction theory).

2. In mixed electrolytes the long-range electrostatic interaction between ions of like or unlike sign requires that all ions be considered in calculating the charge density throughout the solution. This is accomplished by making the activity coefficient a function of the total ionic strength $I$.

Empirical interaction constants ( $B_{M X}$ ) are calculated for single salt solutions from measured activity coefficients, molalities of the salt's ions and total ionic strength. Activity coefficients can be measured by osmotic pressure and/or vapor pressure experiments which are briefly described in Reference 7. The measured quantities are substituted into Equation 5 and values for $B_{M X}$ can be calculated. Similar experiments on salt mixtures indicate that the effects in pure salt solutions can be added to describe mixed salt solutions.

The equation for the mean activity coefficient of a salt MX in a mixed salt solution is:

$$
\begin{aligned}
\log \gamma_{f M X}= & -A_{Y} Z_{+} Z_{-} \frac{I^{1 / 2}}{I+I^{1 / 2}}+\frac{v+}{v_{+}+\nu_{-}} \sum_{X} B_{M X} m_{X}^{\prime} \\
& +\frac{v_{-}}{v_{+}+\nu_{-}} \sum B_{M} X^{m_{M}}
\end{aligned}
$$


where

$$
\begin{aligned}
& \mathrm{A}_{Y}=\text { Debye-Huckel theoretical coefficient } \\
& \mathrm{Z}_{+}=\text {charge on cation of salt } \mathrm{MX} \\
& \mathrm{Z}_{-}=\text {charge on anion of salt } \mathrm{MX} \\
& \mathrm{I}^{\prime}=\text { total ionic strength of salt mixture } \\
& \nu_{+}=\text {number of cations present when salt MX dissociates } \\
& \nu_{-}=\text {number of anions present when salt MX dissociates } \\
& { }_{\mathrm{B}_{M X}}=\text { adjustable constant of each salt evaluated at } I \\
& \mathrm{~m}_{\mathrm{X}^{\prime}}=\text { molality of individual ion } \mathrm{X}^{\prime}
\end{aligned}
$$

The first term in the equation is the Debye-Huckel term; the second is the sum of the interactions between the cation $M$ and all the other anions present; and the third term is the sum of the interactions between the anion $\mathrm{X}$ and all the other cations present.

Tables of $B_{M X}$ for 67 common 1-1 salts and $601-2$ or 2-1 salts are available in the literature. 7 The nomenclature 1-1, 1-2, etc. refers to the charges on the cation and anion, respectively, of the salt. For example, $\mathrm{NaCl}$ is a $1-1$ salt and $\mathrm{Na}_{2} \mathrm{SO}_{4}$ is a 1-2 salt.

A check of Equation 5 on experimental data was made to determine the validity of this approach. First, pure salt solutions were checked and the empirical equations proved satisfactory (Table 7). Next, salt mixtures were studied. The experimental

TABLE 7. MEASURED AND ESTIMATED ACTIVITY COEFFICIENTS FOR PURE SALT SOLUTIONS

\begin{tabular}{lrl}
$\gamma_{\mathrm{KCl}}$ & Exp. Value & $\underline{E u_{1} .4}$ \\
\hline $.1 \mathrm{~m}$ & .770 & .770 \\
$1 \mathrm{~m}$ & .605 & .6045 \\
$3 \mathrm{~m}$ & .590 & .570 \\
$5 \mathrm{~m}$ & & .592 \\
$\gamma_{\mathrm{NaNO} 3}$ & & \\
\hline $1 \mathrm{~m}$ & .573 & .761 \\
$1 \mathrm{~m}$ & .548 & .549 \\
$3 \mathrm{~m}$ & $.737-.438$ & .4375 \\
$5 \mathrm{~m}$ & .386 & .387
\end{tabular}


mean ionic activity coefficient of $\mathrm{NaCl}$ in a $\mathrm{NaCl}-\mathrm{Na}_{2} \mathrm{SO}_{4}$ solution was compared with Equation 5. From Table 8 it can be seen that the agreement is good.

TABLE 8. MEASURED AND ESTIMATED ACTIVITY COEFFICIENTS FOR A $\mathrm{NaCl}-\mathrm{Na}_{2} \mathrm{SO}_{4}$ SOLUTION

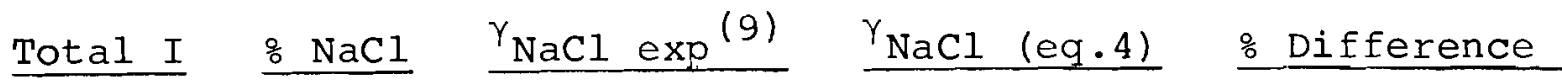

$1 \mathrm{~m}$

$74.70 \%$

.634

.637

$+.4 \%$

$1 \mathrm{~m}$

$12.13 \%$

.601

.588

$-2.0 \%$

$3 \mathrm{~m}$

$75.00 \%$

.639

.663

$+3.6 \%$

$25.06 \%$

.556

.568

$+2.2 \%$

The experimental mean ionic activity coefficient of $\mathrm{NaCl}$ in a $\mathrm{NaCl}-\mathrm{MgCl}_{2}$ solution was compared with Equation 5, as well as the experimental mean ionic activity coefficient of $\mathrm{Na}_{2} \mathrm{SO}_{4}$ in $\mathrm{NaCl}-\mathrm{Na}_{2} \mathrm{SO}_{4}$ solution. From Tables 9 and 10 it can be seen that the agreement is good.

TABLE 9. MEASURED AND ESTIMATED ACTIVITY COEFFICIENTS FOR A NaCl-MgCl 2 SOLUTION

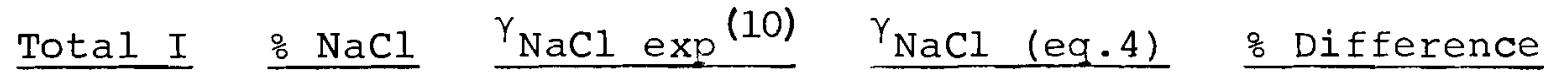

$\begin{array}{ccccc}.5 \mathrm{~m} & 35.64 & .702 & .683 & -2.7 \% \\ 1.0 \mathrm{~m} & 75.21 & .661 & .658 & -0.5 \% \\ 1.0 \mathrm{~m} & 33.15 & .670 & .648 & -3.3 \% \\ 3.0 \mathrm{~m} & 78.53 & .730 & .724 & -0.8 \% \\ 3.0 \mathrm{~m} & 33.94 & .758 & .741 & -2.2 \% \\ 5.0 \mathrm{~m} & 83.17 & .873 & .892 & +2.2 \% \\ 5.0 \mathrm{~m} & 25.96 & .889 & .951 & +7.0 \%\end{array}$


TABLE 10. MEASURED AND ESTIMATED ACTIVITY COEFFICIENTS FOR A NaCl-Na $\mathrm{SO}_{4}$ SOLUTION

\begin{tabular}{|c|c|c|c|c|}
\hline Total I & $8 \mathrm{Na}_{2} \mathrm{SO}_{4}$ & $\gamma_{\mathrm{Na}_{2} \mathrm{SO}_{4}}$ exo ${ }^{(11)}$ & $\gamma_{\mathrm{Na}_{2} \mathrm{SO}_{4}}(\mathrm{eq} .1)$ & \& Difference \\
\hline $1.0 \mathrm{~m}$ & $90 \%$ & .317 & .301 & $-5.1 \frac{8}{8}$ \\
\hline $1.0 \mathrm{~m}$ & $50 \%$ & .327 & .320 & $-2.1 \%$ \\
\hline $1.0 \mathrm{~m}$ & $9.58 \%$ & .338 & .341 & $+0.9 \%$ \\
\hline
\end{tabular}

Therefore, the above checks, Tables 7 through 10, indicate that Equation 5 does in fact predict the activity coefficients of mixed salt solutions over a range of concentrations similar to those encountered in the Hanford system.

Unfortunately no activity coefficient data on mixed nitrate salts were found in the literature and thus the validity of Equation 5 on mixed nitrate salts could not be checked without initiating new experiments. Since high nitrate content waste solutions are common on the Hanford Reservation, several experimental nitrate studies were performed before adopting Equation 5 to estimate activity coefficients.

A calcium nitrate-sodium nitrate system was prepared at five different ionic strengths. At each ionic strength the percentages of sodium nitrate were varied to cover the range 0-100 percent. Specific ion electrodes were used to experimentally determine the activity coefficients of the binary salt mixtures. Huston, Butler and Synnott $9,10,11,12$ describe in detail the use of specific ion electrodes to measure the activity of ions in solution. The specific ion electrode measures the activity of the ion of interest; by comparing the activity in the solution with a reference solution in which both the activity and activity coefficients have been independently determined, and knowing the concentration of the measured ion, one can determine the activity coefficient of the ion from the measured activity. The mean activity coefficients for sodium nitrate in the mixed electrolyte were calculated using the following equation based on the works of Butler, et al. mentioned previously:

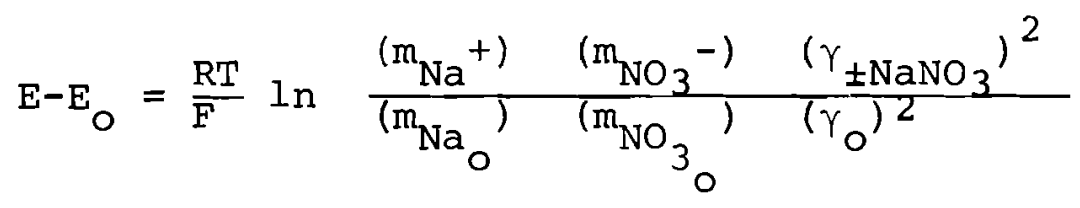


where the subscript (o) represents the pure sodium nitrate reference solution. The molalities of the reference solution $\mathrm{m}_{\mathrm{Na}}$ and $\mathrm{m}_{\mathrm{NO}_{3}}$ and the molalities of the mixed solution $\mathrm{m}_{\mathrm{Na}}{ }^{+}$ and $\mathrm{m}_{\mathrm{NO}_{3}}$ - are $\mathrm{O}_{\text {known }}$ values. $\gamma \mathrm{O}$ is the activity coefficient of the pure sodium nitrate solution. $\gamma o$ is obtained from the literature. ${ }^{8}$ The experimental millivolt difference $E-E_{O}$ is measured with specific ion electrodes and $\gamma_{ \pm \mathrm{NaNO}_{3}}$ calculated.

The electromotive force $\mathrm{E}$ is directly related to the activity using the Nernst equation

$$
E-E^{\prime}=+\frac{R T}{n F} \ln a
$$

where

$$
\begin{aligned}
\mathrm{E} & =\text { electrode potential } \\
\mathrm{E}^{\prime} & =\text { reference electrode potential } \\
\mathrm{a} & =\text { activity of the solution }
\end{aligned}
$$

The mean activity coefficients for calcium nitrate in the mixed electrolyte were calculated using Equation 8, which is similar to Equation 6:

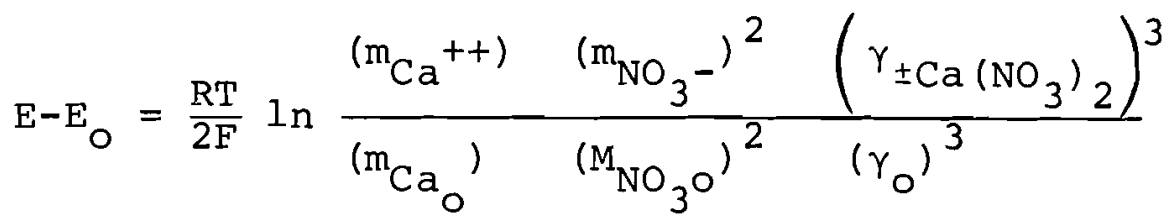

Here the subscripts (0) refer to the pure calcium nitrate reference solution. Activity coefficient results for the sodium-calcium mixed salt system are presented in Table 11, where the experimental activity coefficients are compared to coefficients derived using Equation 5.

It can be seen that the experimental activity coefficients generally agree with the empirically derived values; however, the calcium nitrate activity coefficients in the strong sodium solutions were found to be systematically high. Further experimentation utilizing specific ion electrodes showed that this is caused by a breakdown in the Ca electrode's specificity for calcium. At large $\mathrm{Na} / \mathrm{Ca}$ ratios, sodium is sensed by the calcium electrode. Two methods of describing this interference were found in the literature. Huston and Butler ${ }^{12}$ use observed activity coefficients determined by an independent method and observed millivolt readings to determine a parameter for correcting for the $\mathrm{Na}$ interference $(\mathrm{K})$. The value of $\mathrm{K}$ is a function of the ratio $\mathrm{Na} / \mathrm{Ca}$ and total ionic 


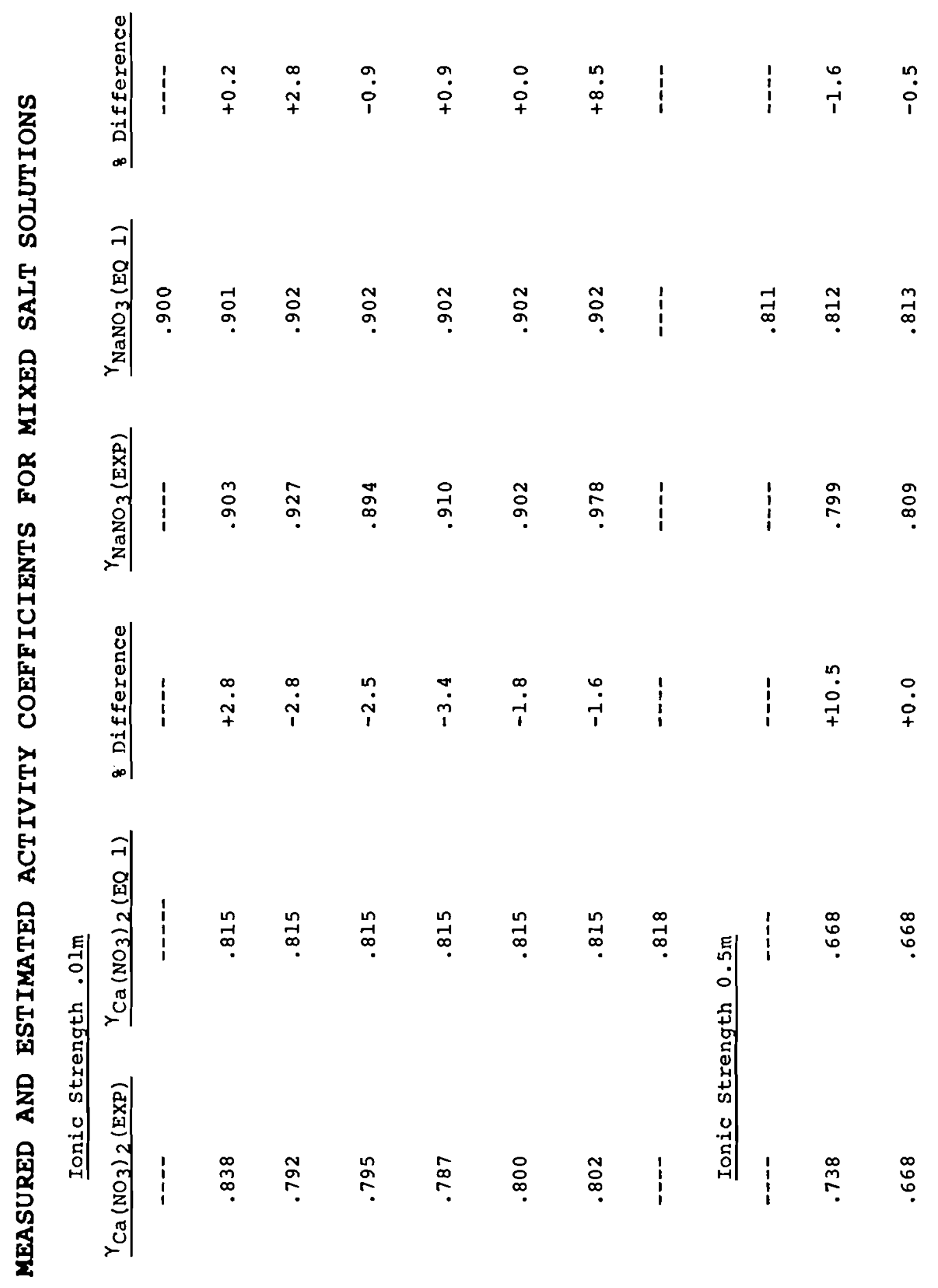

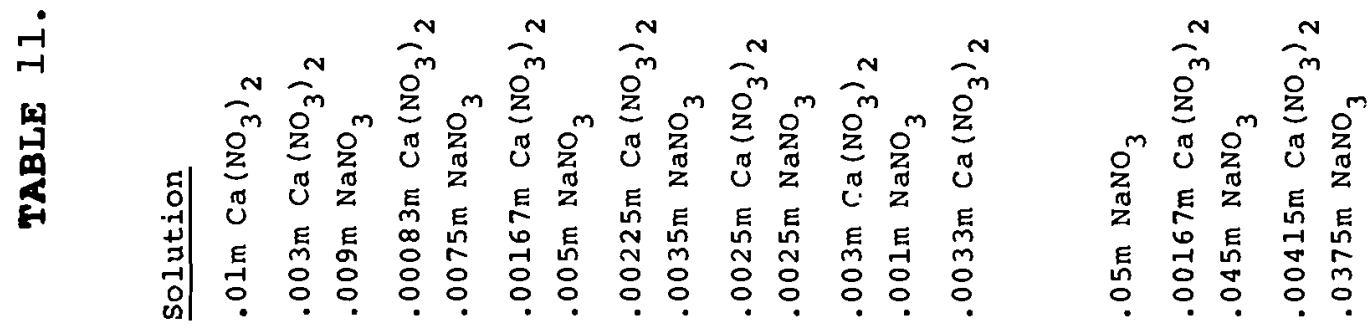


$\frac{2}{y}$

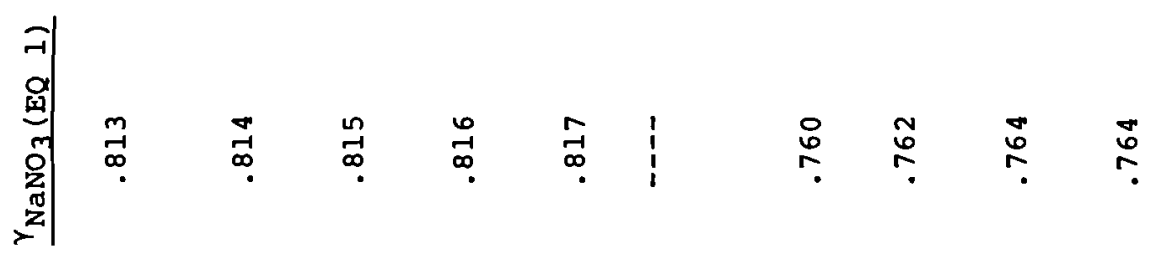

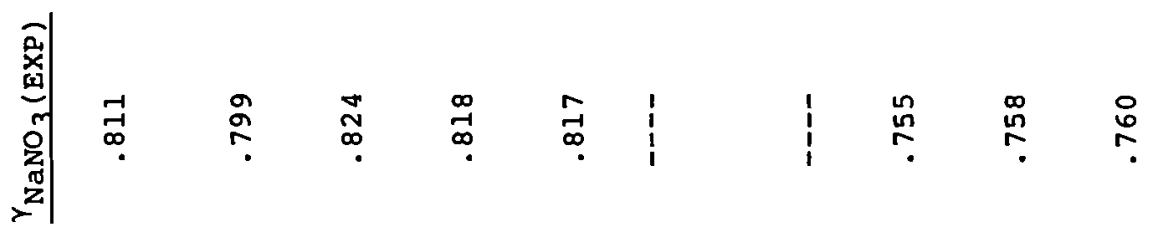

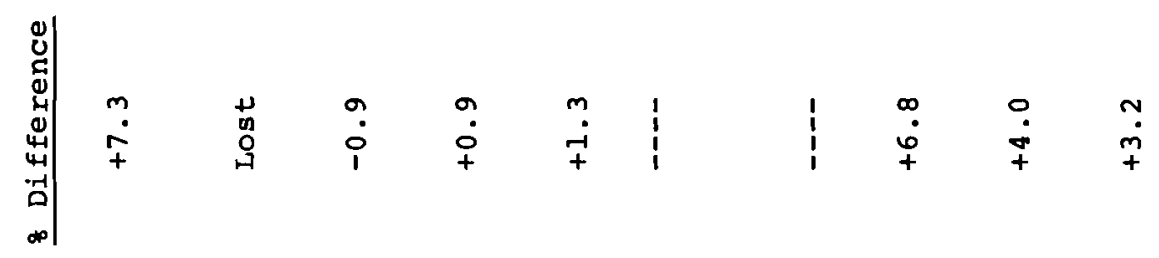

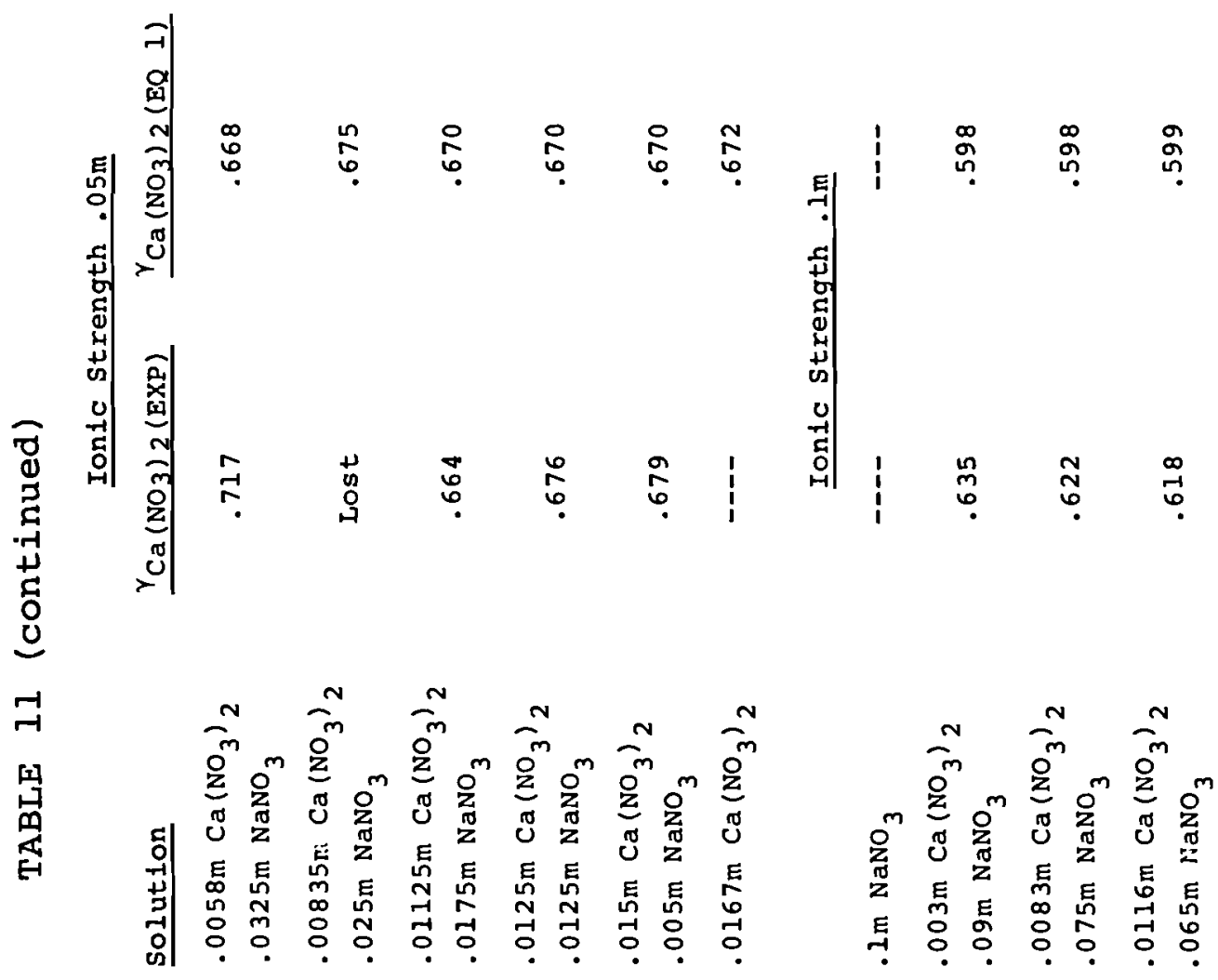




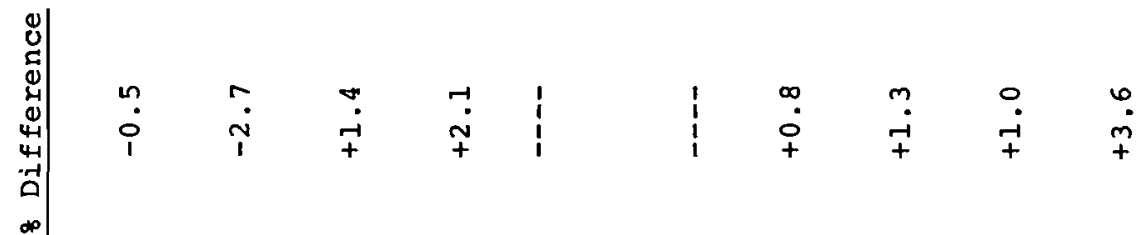

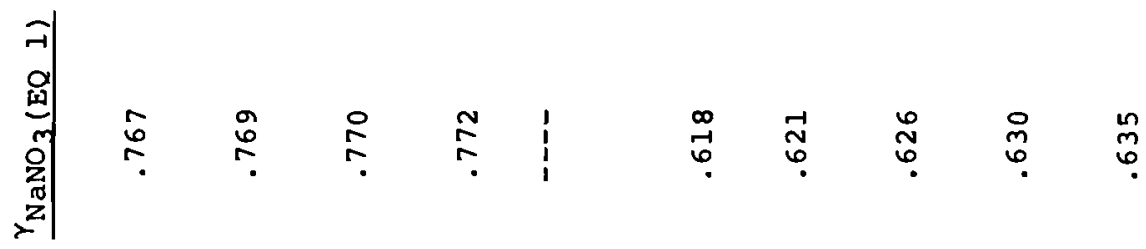

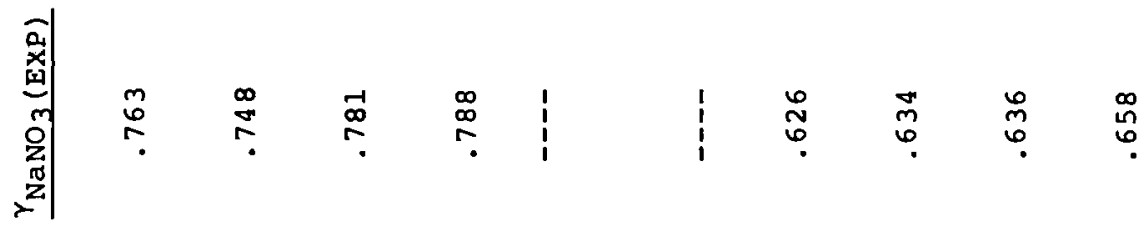

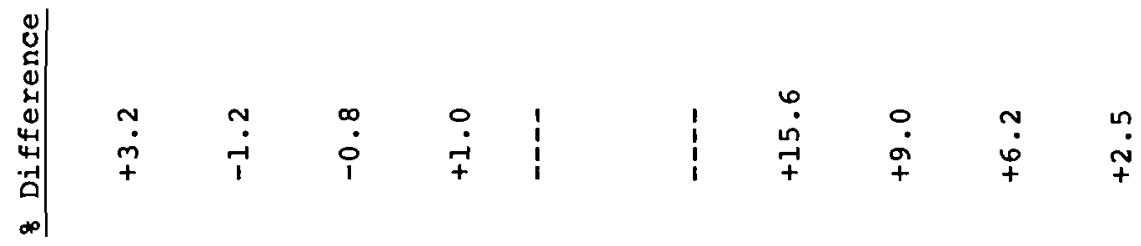

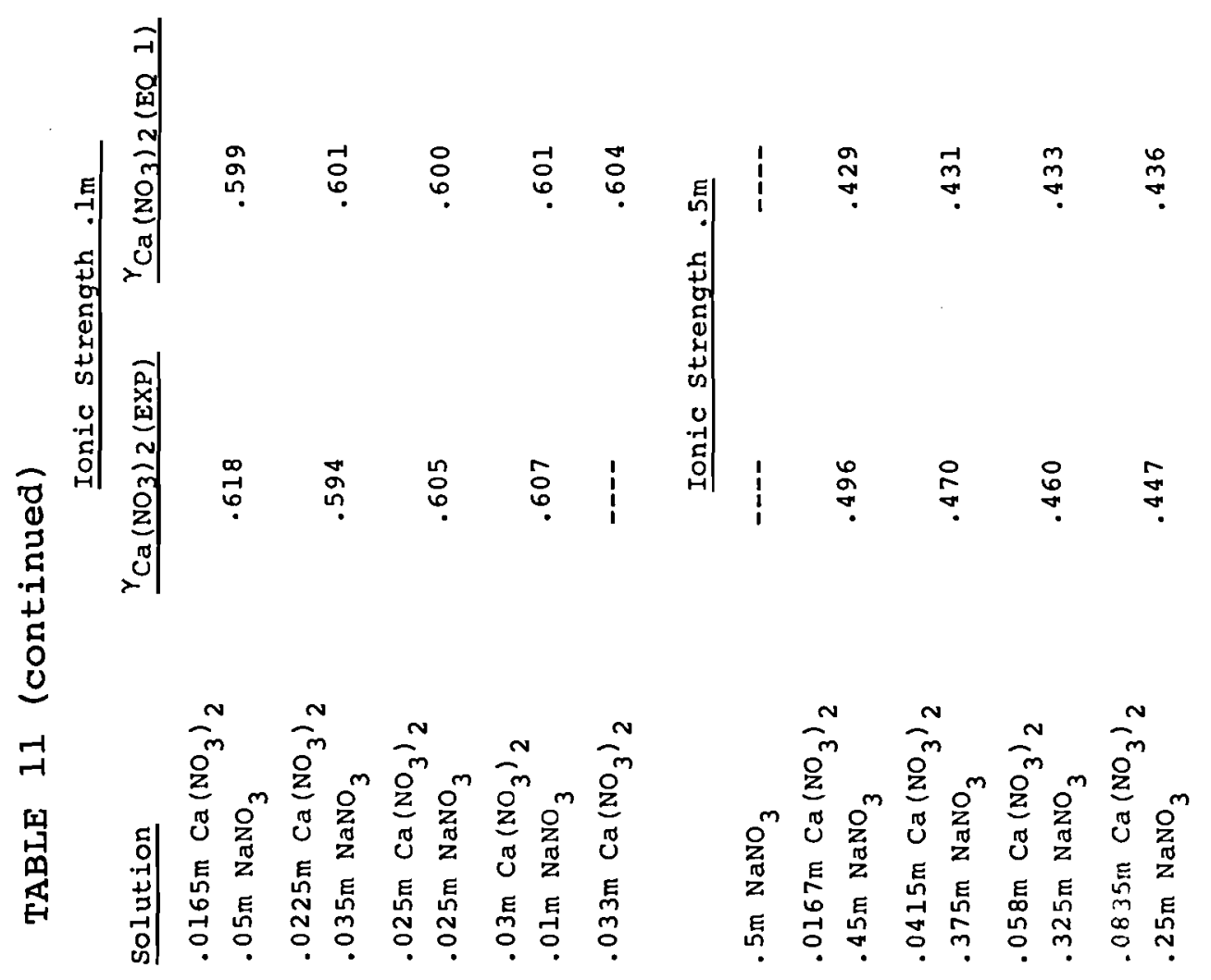




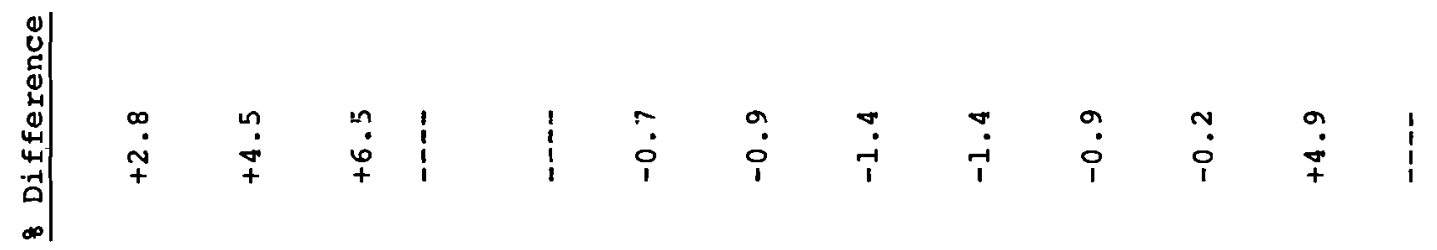

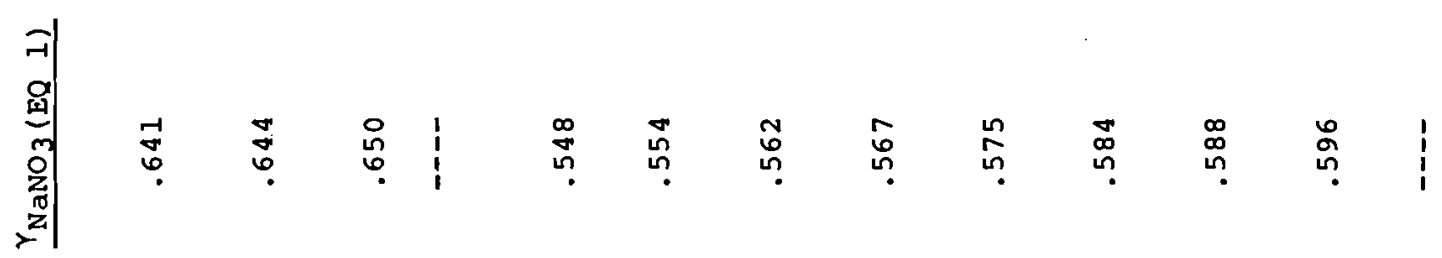

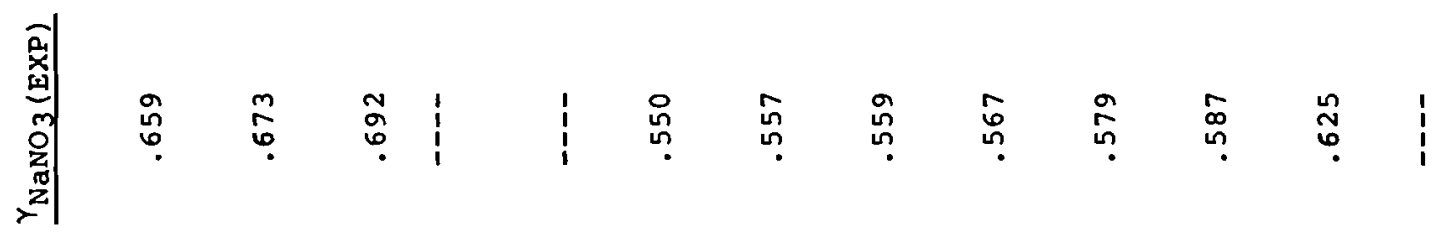

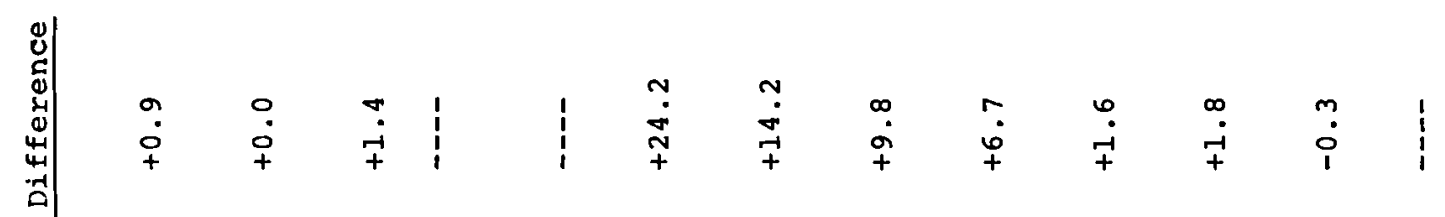

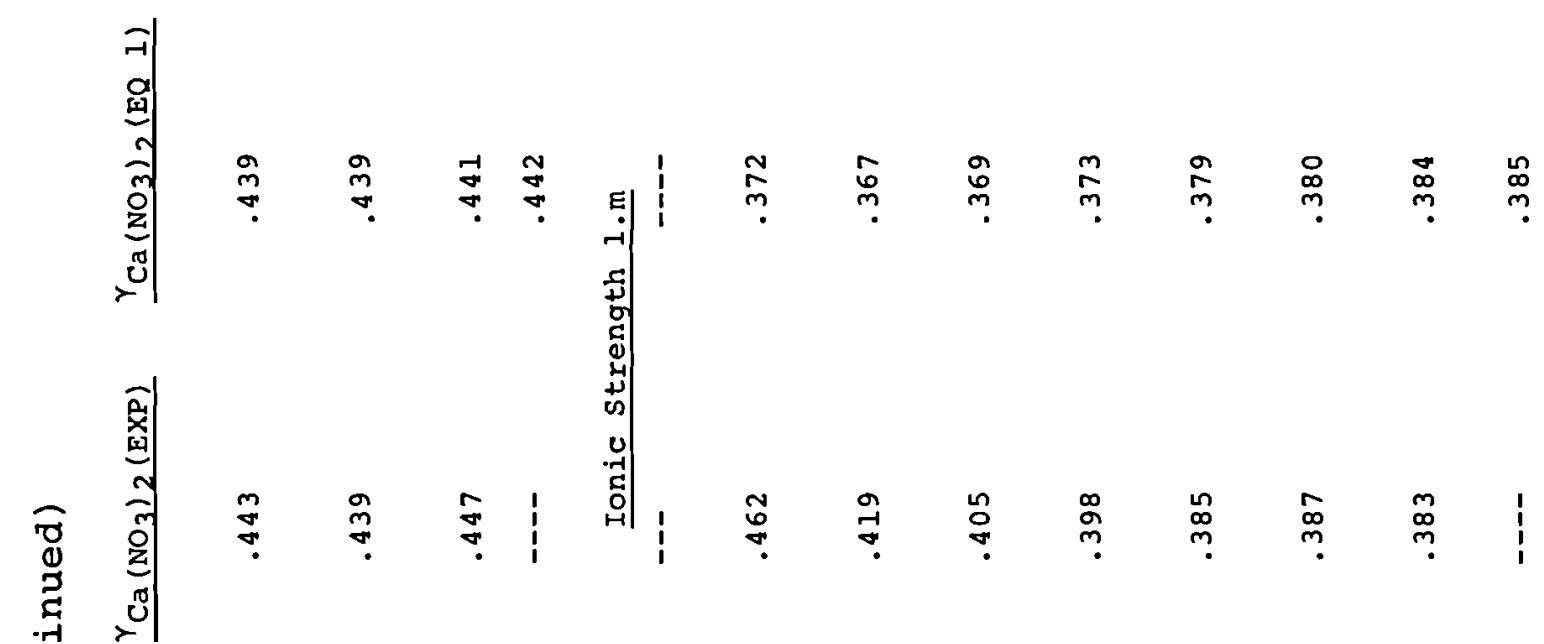
7

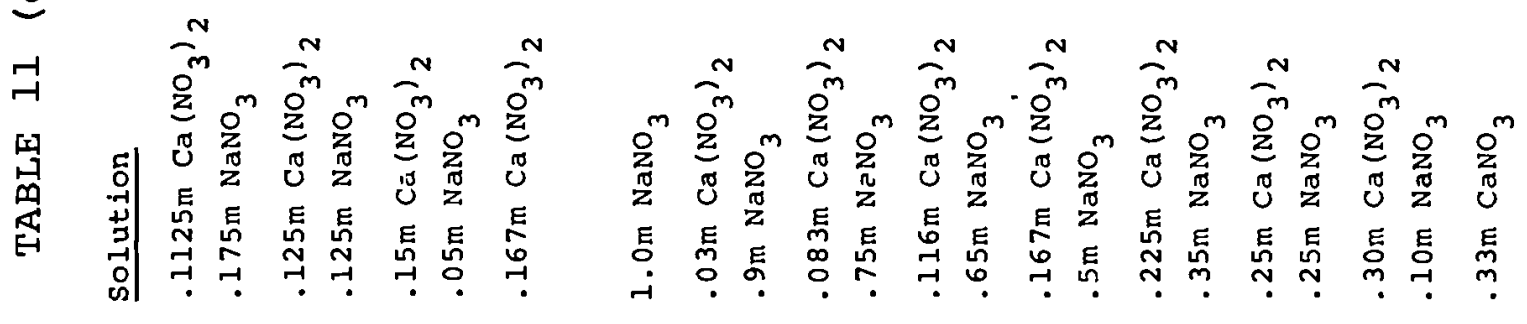


strength. The true equation for a calcium selective ion electrode in the above mixtures would be, according to Huston and Butler: 12

$$
\frac{\mathrm{E}-\mathrm{E}_{\mathrm{O}}=\frac{\mathrm{RT}}{2 \mathrm{~F}} \ln \left[\left(\mathrm{m}_{\mathrm{Ca}}+2\right)\left(\mathrm{m}_{\mathrm{NO}_{3}^{-}}\right)^{2}\left({ }_{ \pm} \mathrm{Ca}\left(\mathrm{NO}_{3}\right)_{2}\right)^{3}+\mathrm{K}\left(\mathrm{m}_{\mathrm{Na}}+\right)\left(\mathrm{m}_{\mathrm{NO}_{3}}\right)^{\gamma^{2}} \pm \mathrm{NaNO}_{3}\right]}{\left(\mathrm{m}_{\mathrm{Ca}}\right)\left(\mathrm{m}_{\mathrm{NO}_{3}}\right)^{2} \mathrm{r}^{3}}
$$

Since $\gamma \pm \mathrm{Ca}\left(\mathrm{NO}_{3}\right)_{2}$ and $\gamma \pm \mathrm{NaNO}_{3}$ experimental values are not known in this case, another method is required. Alternatively, if one has complete confidence in Equation 5, values of mean activity coefficients can be calculated and $\mathrm{K}$ found from Equation 9.

According to Shatkay, 13 the calcium electrode measures a single ion activity coefficient of calcium; however, the measurement of such single ion activity coefficients is questionable. Shatkay states that the activity of Ca+2 is as valid as the activity of $\mathrm{H}^{+}$by electrode (pH). According to Shatkay's convention, the calcium electrode is only influenced by cations in solution. Equation 5 for calculating the single ion activity coefficient of $\mathrm{Ca}^{++}$reduces to

$$
\log \gamma_{M_{i}}=-A_{Y} z_{i}^{2} \frac{I^{1 / 2}}{1+I^{1 / 2}}+\sum_{X} B_{M X}{ }^{\prime m} X^{\prime}
$$

Using Shatkay's notation, Equation 8 becomes

$$
E-E_{0}=\frac{R T}{2 F} \ln \left[\frac{\left(\left(m_{\mathrm{Ca}}+2\right)\right)\left(\left(\gamma_{\mathrm{Ca}}+2\right)\right)}{\left(\left(m_{\mathrm{Ca}_{\mathrm{o}}}\right)\right)\left(\left(\gamma_{\mathrm{Ca}_{\mathrm{O}}}\right)\right)}\right]
$$

To validate Shatkay's approach an experiment was conducted in which the interfering salt concentration was varied while the measured salt concentration was kept constant. When the calcium specific ion electrode was being used the calcium concentration of the salt mixture was held constant and the interfering sodium ion was varied. Using this approach the effects on the specific ion electrode of other ions can be determined. The effects are quantified as an interference factor $K_{i}$. In this case the interference factor is sodium's 
effect on the calcium electrode. The values of $\gamma_{\mathrm{Ca}}{ }^{+2}$ and $\gamma_{\mathrm{Na}}{ }^{+}$ were calculated from Equation 10 and used in the following equation to determine an interference factor $\mathrm{K}$ :

$$
E-E_{0}=\frac{R T}{2 F} \ln \frac{\left[\left(m_{\mathrm{Ca}^{+}}+2\right)\left(\gamma_{\mathrm{Ca}}+2\right)+\mathrm{K}_{\mathrm{Na}}\left(\gamma_{\mathrm{Na}}+\right)\left(\mathrm{m}_{\mathrm{Na}}{ }^{+)}\right]\right.}{\left(\mathrm{m}_{\mathrm{Ca}}\right)\left(\gamma_{\mathrm{Ca}}\right)}
$$

Using the known reference solution values (pure calcium salt solutions), sample values (the mixed salt solutions), and calculated $\gamma_{\mathrm{Ca}}+2$ and $\gamma_{\mathrm{Na}}+\mathrm{a}$ value of $\mathrm{K}_{\mathrm{Na}}$ was found from the measured $\mathrm{E}-\mathrm{E}_{\mathrm{O}} \cdot$. The value of $\mathrm{K}_{\mathrm{Na}}$ was found to be independent of jonic strength and dependent on the concentration ratio $\left(\mathrm{Na}^{+}\right) /\left(\mathrm{Ca}^{+2}\right)$. Results were:

$$
\begin{aligned}
& \frac{\text { Ratio }}{\mathrm{Na} / \mathrm{Ca}}<30 \quad \frac{\mathrm{K}_{\mathrm{Na}}}{0} \\
& \begin{array}{ll}
\mathrm{Na} / \mathrm{Ca}=30 & 0.007
\end{array} \\
& \mathrm{Na} / \mathrm{Ca}=300 \quad 0.002 \\
& \mathrm{Na} / \mathrm{Ca}=3000 \quad 0.003
\end{aligned}
$$

The above corrections make the measured data of Table 11 reasonably compatible with Equation 5. For example, the solution $0.9 \mathrm{M} \mathrm{NaNO}_{3}-0.033 \mathrm{M} \mathrm{Ca}\left(\mathrm{NO}_{3}\right)_{2}$ has an observed, uncorrected $\gamma_{ \pm \mathrm{Ca}}\left(\mathrm{NO}_{3}\right) 224.2$ percent higher than predicted. Using Equation 12 combined with a form of Equation 10 for the anion activity coefficient $\gamma_{\mathrm{NO}_{3}}$, the corrected value for $\gamma_{ \pm \mathrm{Ca}}\left(\mathrm{NO}_{3}\right) 2$ is 0.377 , which is only 1.3 percent high. Calclium interference on the sodium electrode was not studied in detail since results on the measured solutions without correction were satisfactory (see Table ll).

In order to check the validity of Equation 5, a second salt mixture, $\mathrm{NaNO}_{3}-\mathrm{KNO}_{3}$, was analyzed to experimentally determine the activity coefficients of potassium salts. The experimental design was similar to the calcium-sodium salt system described. Sets of solutions of varying ionic strengths with varying ratios of sodium to potassium (as shown in Table 12) were measured.

The sodium electrode functioned properly with a small potassium interference at $\mathrm{K} / \mathrm{Na} \geq 9$. The value of $\mathrm{K}_{\mathrm{K}}$ does not seem to be as independent of ionic strength as is the sodium interference on the calcium electrode. Tentative values of $\mathrm{K}_{\mathrm{K}}$ for potassium interference on the sodium electrode are: 


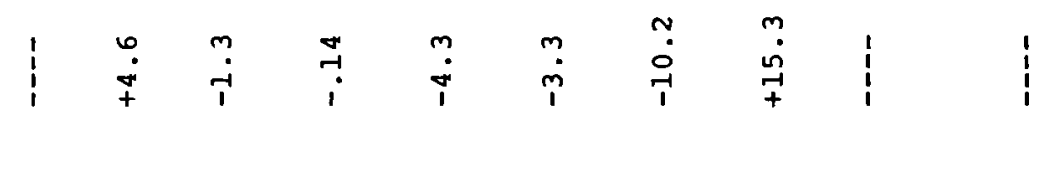

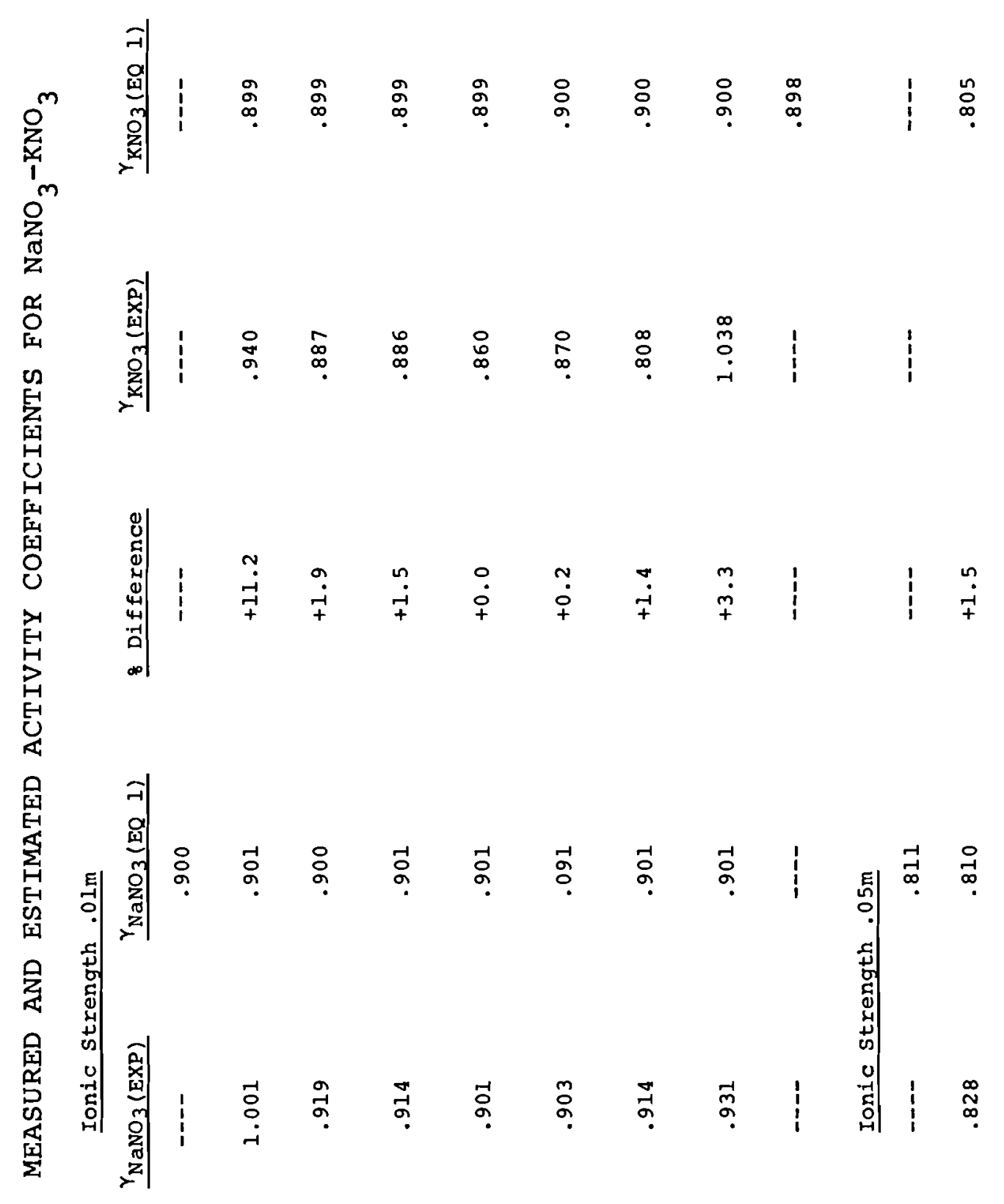

กี

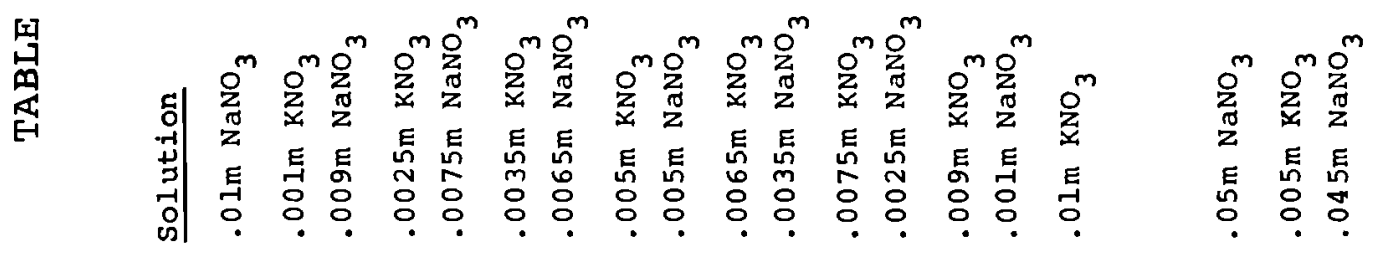


0
0
5
0
0
4
4
4
-1
0
$\infty$

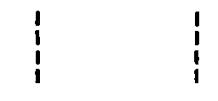

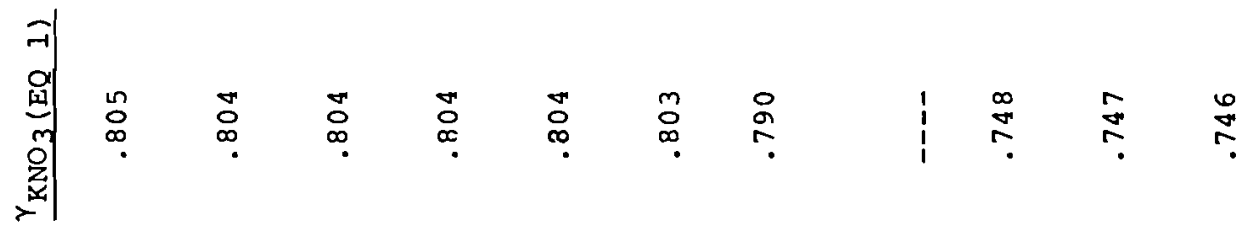

.

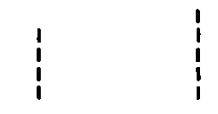

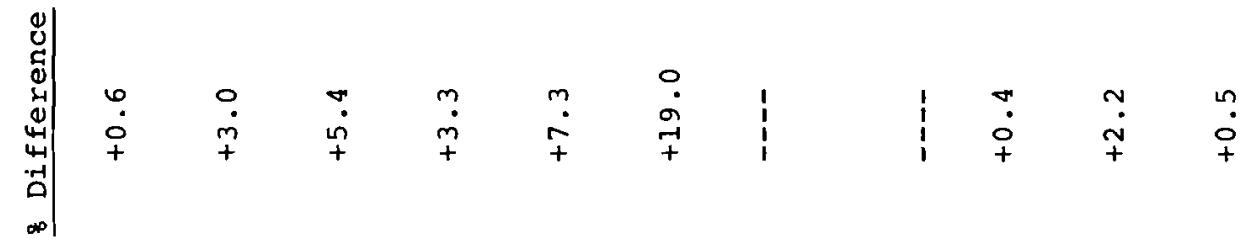

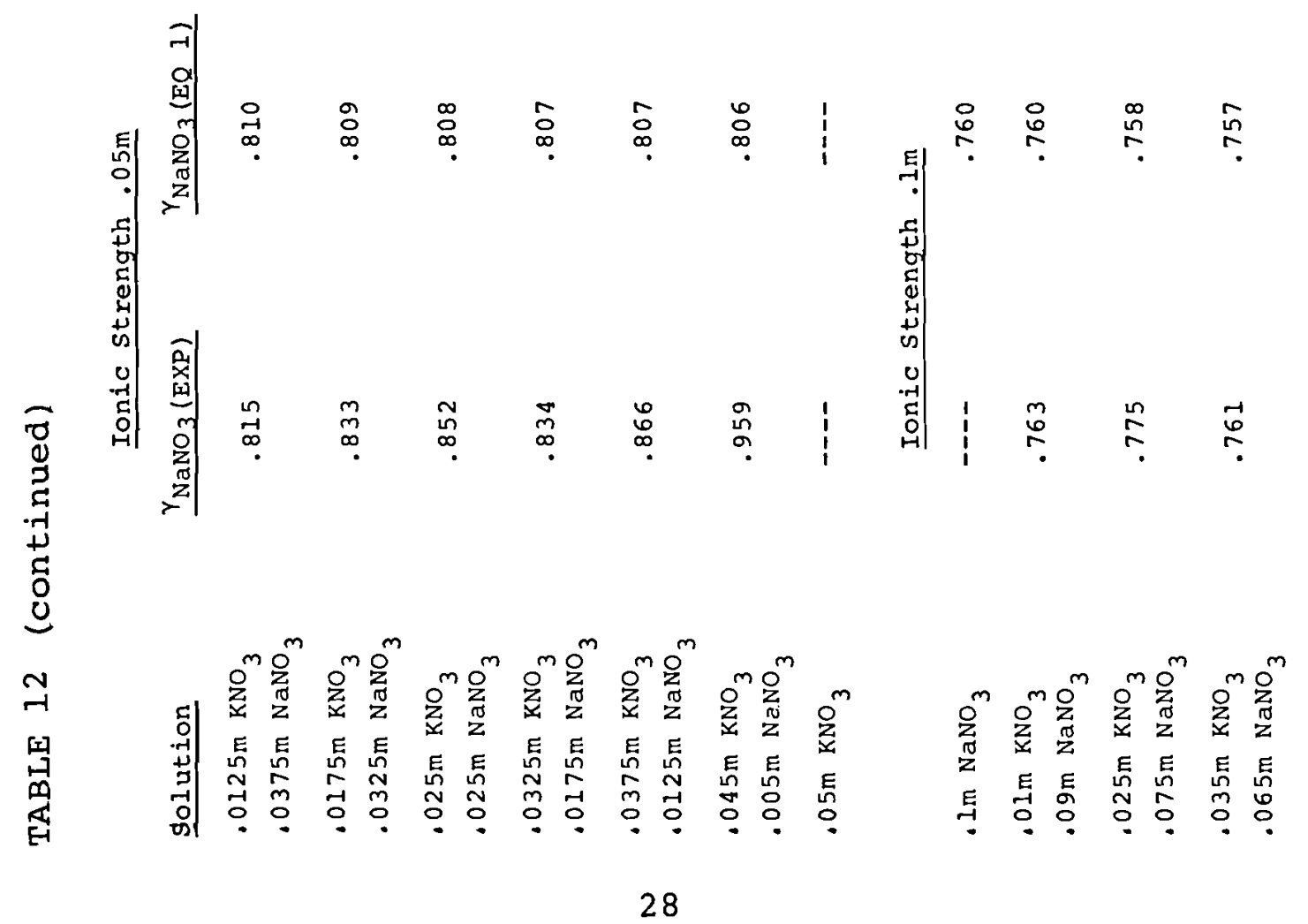




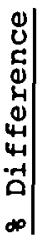

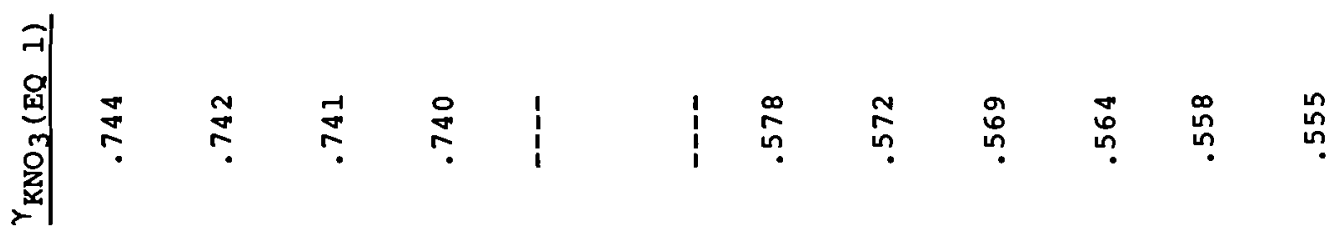

䒽|

1

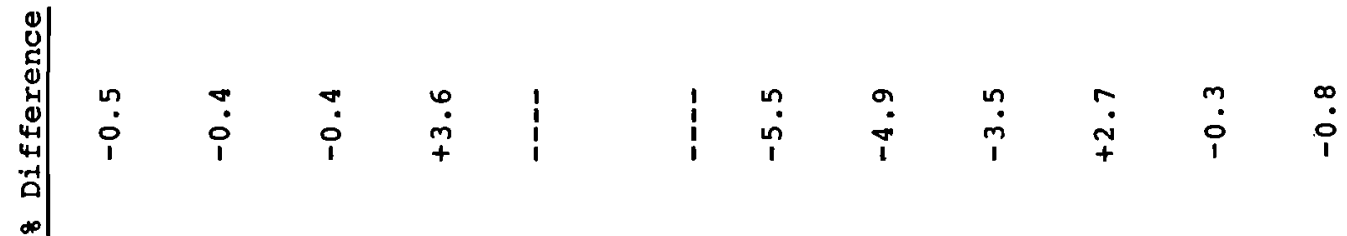

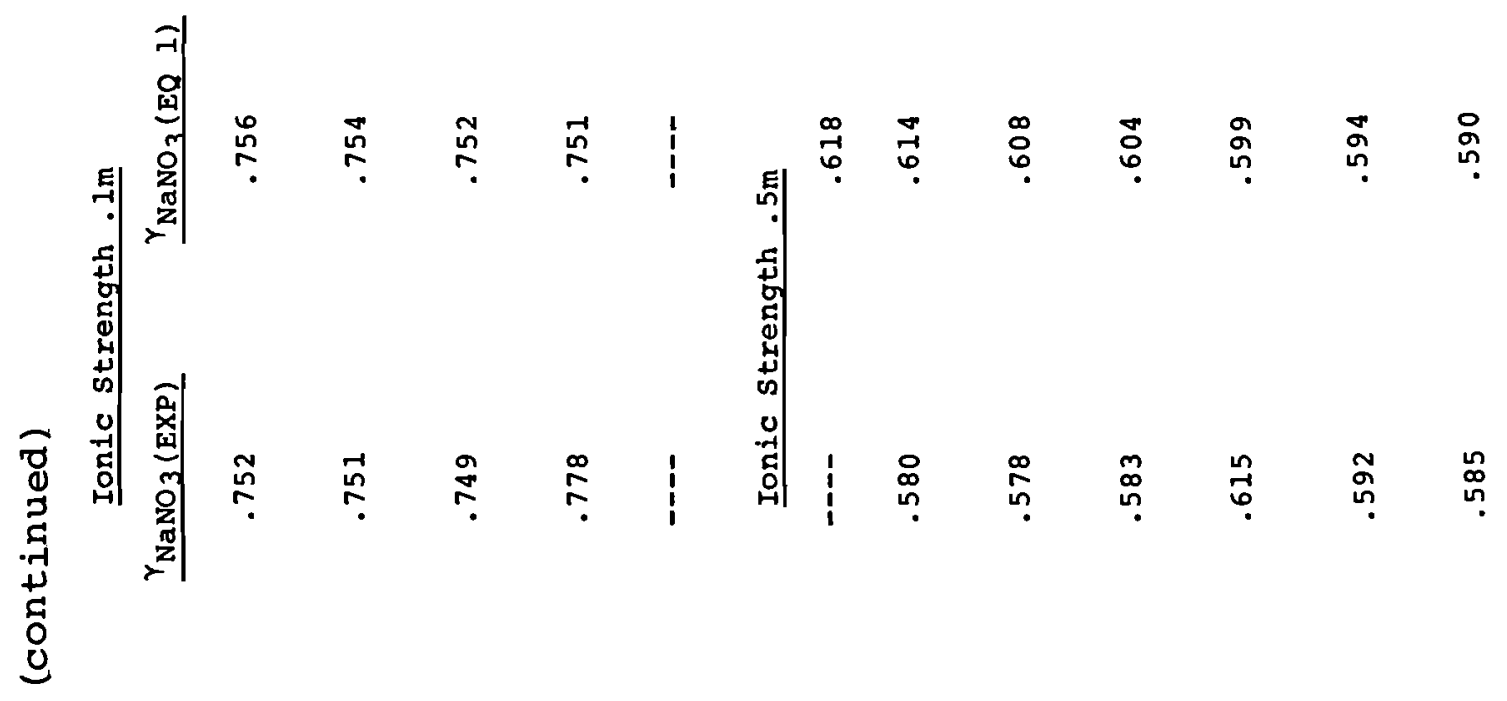

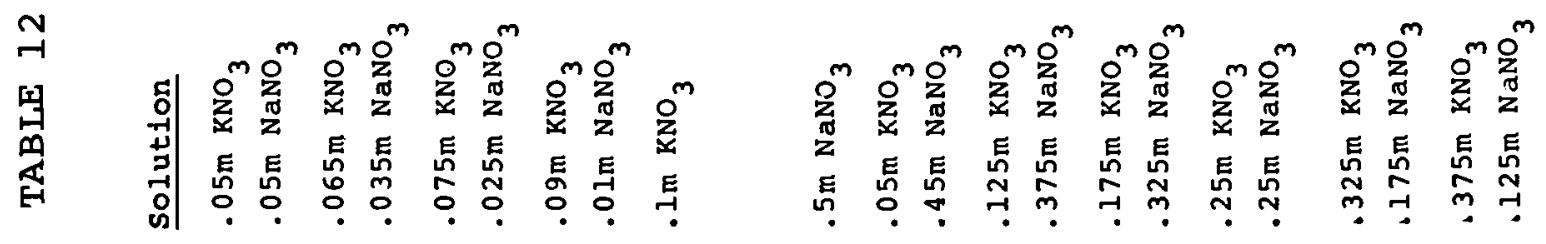


:

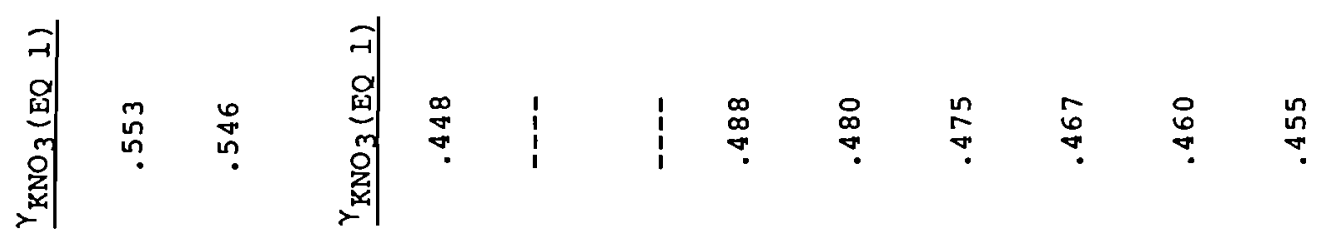

畜 11

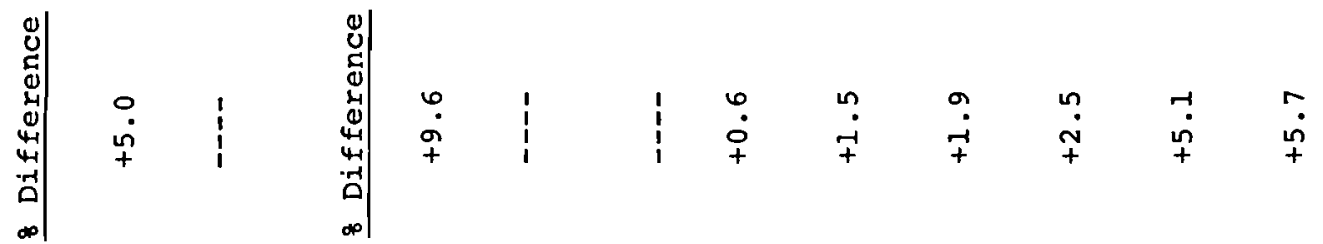

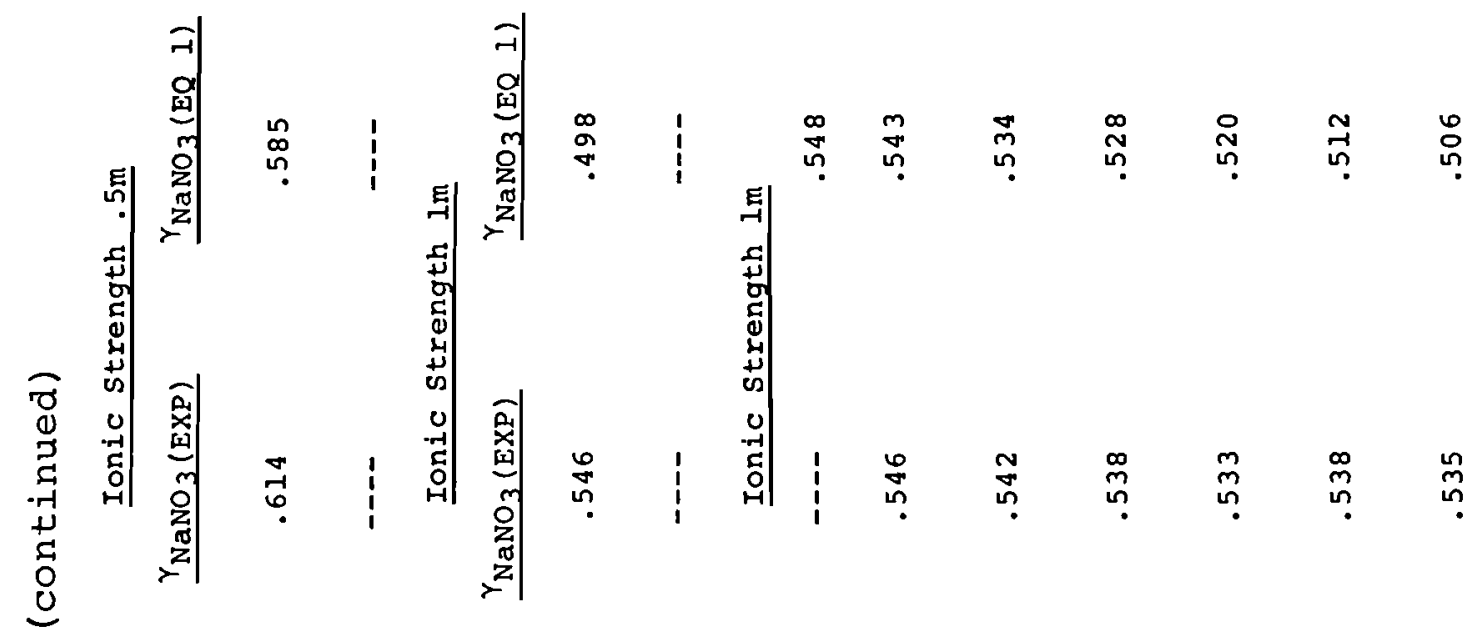

ज

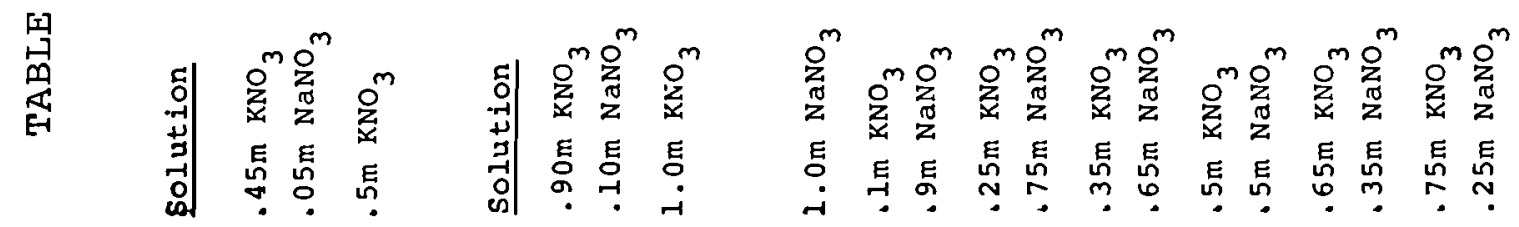


Ratio

$$
\begin{array}{lll}
\mathrm{K} / \mathrm{Na}=10 & \mathrm{~K}_{\mathrm{K}}=0.0093 \\
\mathrm{~K} / \mathrm{Na}=50 & \mathrm{~K}_{\mathrm{K}}=0.0055
\end{array}
$$

The potassium electrode appeared to malfunction above an ionic strength of 0.025 . Consultation with the manufacturer suggested that mislabeled electrode parts might be the cause. New ionic exchange solution and membranes were obtained for the potassium electrode and new outer filling solution for the reference electrode. Experiments with the new components showed little improvement, however. The $1 \mathrm{M}$ binary solutions measured within $3 \mathrm{mv}$ of each other, suggesting that the electrode is totally nonselective at this ionic strength. The electrode functioned properly for pure solutions of $\mathrm{KCl}$ but not for pure solutions of $\mathrm{KNO}_{3}$. Experimental and measured activity coefficients are summarized in Table 12 and it can be seen that measured and estimated activity coefficients for $\mathrm{NaNO}_{3}$ are good.

Experimental data for potassium activity coefficients was not sufficient to validate Equation 5. But considering the agreement of this study's data for the sodium and calcium activity coefficients and the independent data presented in Tables 7 through 10, Equation 5 appears to estimate mean ionic activity coefficients of high ionic strength mixed salt systems encountered on the Hanford Reservation.

In order to utilize Equation 5 to predict the activities of the most important chemical species reacting in the soil-waste liquid regime present at Hanford, several $\mathrm{B}_{\mathrm{MX}}$ specific interaction terms need to be known. As previously stated, comprehensiye tables of $\mathrm{B}_{\mathrm{MX}}$ constants can be found in the literature. 7,8 Unfortunately, the specific interaction terms for a few important chemical species (for example, CaSO 4 ) are not found in the mentioned literature. The value of
$\mathrm{B}_{\mathrm{CaSO}}$ was determined from articles by Gardner and Glueckauf 14,15 and $1 \mathbf{s}$ presented in Table 13. The values were calculated utilizing Equation 5, Gardner and Glueckauf's measured activity coefficients and the known molal concentrations of the species in the solutions. With all the known quantities, the $\mathrm{B}_{\mathrm{CaSO} 4}$ can be determined by back calculation.

To experimentally verify the calculated $\mathrm{B}_{\mathrm{CaSO}}$ values an experiment utilizing specific ion electrodes was performed.

For the experimental verification three binary mixtures of $\mathrm{CaSO}_{4}-\mathrm{NaNO}_{3}$ at ionic strengths of $0.01 \mathrm{M}, 0.05 \mathrm{M}$, and $0.15^{4}$ were checked using the calcium ion electrode. Mixtures 
TABLE 13. EMPIRICAL INTERACTION CONSTANT (BCaSO 4 ) FOR $\mathrm{CaSO}_{4}$ AS A FUNCTION OF IONIC STRENGTH

\begin{tabular}{|c|c|}
\hline$I$ & ${ }^{\mathrm{B}} \mathrm{CaSO}_{4}$ \\
\hline $4 \times 10^{-5}$ & -43.24 \\
\hline $1.2 \times 10^{-4}$ & -42.95 \\
\hline $2.0 \times 10^{-4}$ & -43.17 \\
\hline $4.0 \times 10^{-4}$ & -53.54 \\
\hline $1.2 \times 10^{-3}$ & -46.00 \\
\hline $2.0 \times 10^{-3}$ & -41.50 \\
\hline $4.0 \times 10^{-3}$ & -32.55 \\
\hline $1.0 \times 10^{-2}$ & -19.2 \\
\hline $1.2 \times 10^{-2}$ & -18.75 \\
\hline $2.0 \times 10^{-2}$ & -13.30 \\
\hline $4.0 \times 10^{-2}$ & -7.52 \\
\hline $5.0 \times 10^{-2}$ & -6.0 \\
\hline $6.0 \times 10^{-2}$ & -5.17 \\
\hline $1.29 \times 10^{-1}$ & -4.59 \\
\hline $1.5 \times 10^{-1}$ & -1.3 \\
\hline $2.07 \times 10^{-1}$ & -3.77 \\
\hline $3.44 \times 10^{-1}$ & -3.13 \\
\hline $6.97 \times 10^{-1}$ & -1.85 \\
\hline $8.44 \times 10^{-1}$ & -1.58 \\
\hline 1.01 & -1.86 \\
\hline 2.24 & -0.84 \\
\hline 3.09 & -0.84 \\
\hline 4.35 & -0.79 \\
\hline
\end{tabular}

* Experimentally determined value 
of $\mathrm{Ca}\left(\mathrm{NO}_{3}\right)_{2}-\mathrm{NaNO}_{3}$ of the same ionic strengths and calcium concentration were used as the reference solutions. The $\Delta E$ is a measure of the difference of the $\gamma_{\mathrm{Ca}}+2$ between the nitrate and sulfate solutions. From the difference in the activity coefficient between the two solutions the value of $\mathrm{B}_{\mathrm{CaSO}}$ was calculated. The average of $\mathrm{B}_{\mathrm{CaSO}}$ for each ionic strength tested is also given in Table 13. At the two lower ionic strengths, the values of $\mathrm{B}_{\mathrm{CaSO}_{4}}$ are in good agreement with the values calculated from the literature. The $0.15 \mathrm{M}$ data are again affected by sodium interference on the calcium electrode.

In summary, the use of specific ion electrodes to measure activity coefficients has been somewhat complicated by interference effects. To obtain accurate activity coefficients, many solutions must be measured to determine interference constants, $K_{i}$. Greater precaution is warranted than is usually stated in the operation manuals. The tested empirical equation (Equation 5) does predict the activity coefficients of salts in mixtures to ionic strengths of $6 \underline{M}$ or higher.

Values of the mean activity coefficients of the solute constituents can be determined from Equation 5, the tables of $\mathrm{B}_{\mathrm{MX}}$, and the concentrations of solute constituents generated in the PERCOl model. The PERCOL computer program can be set up to automatically calculate the desired activity coefficients. At present the PERCOL model includes the $\mathrm{B}_{\mathrm{MX}}$ values for all sodium, potassium, magnesium and calcium salts of the anions $\mathrm{NO}_{3}, \mathrm{SO}_{4}, \mathrm{Cl}$, and $\mathrm{HCO}_{3}$. Experimental verification has been carried out either by the work described above or by other methods for most of the salts. Additional salts can be added to the model if they are required.

ESTIMATION OF KdSr IN THE HANFORD GROUNDWATER SYSTEM AS A FUNCTION OF SOIL PERMEABILITY

Due to the mixing of the relatively small volume of solution from the vadose zone with the much larger groundwater reservoir volume and to hydrodynamic dispersion and diffusion, trace radionuclides entering the groundwater are shortly in a chemical environment approaching that of the groundwater. 16 As these wastes move toward the Columbia River this chemical environment tends to change relatively little since there is limited recharge in this low rainfall region. In such a system the use of a constant $\mathrm{Kd}$ to estimate the transport of a given trace radionuclide may be an economical and viable possibility.16 If the $\mathrm{Kd}$ for a given radionuclide in the groundwater can be related to a soil property which has already been determined for the Hanford Reservation, then the $\mathrm{Kd}$ can be estimated as 
a function of position and used in a transport analysis. In the following study the possibility of correlating KdSr in a chemical system approximating the Hanford Reservation groundwater to permeability of a group of Hanford soils was assessed by Reeve's method. $17^{\prime}$

Laboratory permeabilities of KdSr were determined for five wells on the Hanford Reservation which showed a wide range of measured permeabilities as a function of depth in the saturated zone. Table 14 gives the measured transmissivities, estimated hydraulic thicknesses, and calculated depth-averaged permeabilities for these five wells. Table 15 gives the laboratory measured permeabilities and KdSr values as functions of well depth for one well; tables for four additional wells are in Appendix A.

TABLE 14. ESTIMATED TRANSMISSIVITY, HYDRAULIC THICKNESS AND PERMEABILITY OF SELECTED HANFORD WELLS

\begin{tabular}{|c|c|c|c|}
\hline Well & $\begin{array}{l}\text { Hydraulic Thick- } \\
\text { ness - Et }\end{array}$ & $\begin{array}{l}\text { Transmissivity } \\
\text { ft } 2 / \text { day } \\
\end{array}$ & $\begin{array}{l}\text { Permeability } \\
\mathrm{ft} / \mathrm{day}\end{array}$ \\
\hline $38-65 Q$ & 87 & $4 \times 10^{1}$ & 0.46 \\
\hline $32-70$ & 215 & $1 \times 10^{3}$ & 4.6 \\
\hline $1-18$ & 182 & $1 \times 10^{4}$ & 55 \\
\hline $31-31 P$ & 253 & $2.5 \times 10^{5}$ & 990 \\
\hline $37-43 P$ & 55 & $7.5 \times 10^{4}$ & 1300 \\
\hline
\end{tabular}

To facilitate the correlation the field permeability was assumed to be some multiple of each well's average laboratory permeability. Failure of the laboratory permeability to agree with the field permeability was probably due to structural and layering effects which were modified by sampling and repacking a soil in the laboratory. Each measured laboratory permeability was multiplied by the factor to obtain a corrected sample permeability. Linear regression analysis was used to determine the degree of correlation of KdSr with the corrected permeability. KdSr was found to be related to the corrected permeability by the equation:

$$
\operatorname{KdSr}-3.8 \log \mathrm{K}+11.7
$$


TABLE 15. KdSI AND PERMEABILITY FOR THE SATURATED

ZONE OF WELL 38-65Q

$\begin{array}{lll}\begin{array}{c}\text { Depth } \\ \text { ft }\end{array} & \begin{array}{c}\text { KdSr } \\ \mathrm{ml} / \mathrm{g}\end{array} & \begin{array}{c}\text { Permeability } \\ \mathrm{cm} / \mathrm{min}\end{array} \\ 320 & 12.3 & 0.082 \\ 330 & 11.2 & 0.062 \\ 335 & 12.4 & 0.069 \\ 345 & 22.9 & 0.0030 \\ 350 & 23.4 & 0.0037 \\ 355 & 20.4 & 0.0046 \\ 365 & 19.6 & 0.0049 \\ 370 & 20.6 & 0.0027 \\ 375 & 24.5 & 0.0054 \\ 380 & 23.5 & 0.0052 \\ 385 & 24.7 & 0.0046 \\ 390 & \underline{38.1} & 0.014 \\ \text { Average } & 19.6 & 0.016\end{array}$

where

$$
\begin{aligned}
\mathrm{KaSr} & =\text { distribution coefficient in } \mathrm{ml} / \mathrm{g} \\
\mathrm{K} & =\text { corrected permeability in } \mathrm{ft} / \mathrm{day}
\end{aligned}
$$

The correlation coefficient $(r)$ for Equation 13 was found to be 0.799 , which suggests 64 percent of the variation in KdSr can be accounted for by the variability in the logarithm of the corrected permeability. The standard error of the estimate for Equation 13 was found to be $\pm 3.4 \mathrm{ml} / \mathrm{g}$. Thus, KdSr can be estimated from field transmissivity data.

\section{UNSORBED SOLUTE MOVEMENT THROUGH SOIL COLUMNS}

Hydrodynamic dispersion and diffusion are the only dispersive mechanisms acting upon unsorbed solutes being transported through soil systems. Such systems can be used to estimate the effect of dispersion upon solute transport.18,19 In addition, the movement of unsorbed solutes through a soil $\frac{1}{3}$ can be used to estimate the effective porosity of this soil. 
If some pores in a soil are not interconnected ("dead ended") early breakthrough of solute will result. This loss of transmission porosity must be corrected for in a transport model. The effect of hydrodynamic dispersion has been shown to be flow rate dependent. 19 Thus to assess the effect of dispersion and effective porosity the movement of unsorbed solute ( $\mathrm{H}^{3}$ and $\mathrm{Cl}^{-}$) was measured through a group of five soil columns as a function of flow rate. Experimental details of the experiment are given in BNWL-1721. 3 Column parameters for the five soil columns are given in Table 16 and Appendix Tables B-1, B-2, $\mathrm{B}-3$, and $\mathrm{B}-4$. Figures $3,4,5,6$, and 7 show the normalized movement of unsorbed solutes as functions of the volumes of effluent solution. From these figures it can be seen that the normalized tracer breakthrough at a $\mathrm{C} / \mathrm{Co}$ of 0.5 occurs slightly earlier than would be predicted for unsorbed solutes, i.e., slightly before one pore volume has passed through the columns. This suggests that a small fraction of the soil pores do not transmit solution and that the porosity used in the sorption model should be an effective rather than a bulk porosity. Nielsen and Biggars ${ }^{20}$ have shown that early breakthrough of unsorbed solute is either due to loss of transmitting porosity or to negative sorption of solute.

The movement of slightly or completely unsorbed solutes through soil systems must be measured to estimate the effects of hydrodynamic dispersion and diffusion on solute movement. In addition, if some of the pores are "dead-ended" and do not transmit solution early breakthrough will occur and a correction in the transport model must be made for this loss of transmission porosity. Thus, a group of five column experiments was conducted to obtain data for these determinations. Table 16 gives the operational parameters of one of the five column experiments; tables for the remaining experiments are in Appendix $B$.

Furthermore, good agreement between uncharged ${ }^{3} \mathrm{H}$ (Figure 3) and negatively charged $\mathrm{Cl}$ (Figure 2) breakthrough data was found which suggests that non-transmitting pores, not anion expulsion, is the primary cause of the early breakthrough of these unsorbed solutes. The average porosity reduction as determined by the above data would be 7.7 percent \pm 2 percent.

It can be seen from Figures $3,4,5,6$, and 7 that the shapes of the normalized $\mathrm{Cl}^{-}$curves differ according to solution velocity; the greater the solution velocity the less the effect of dispersion. These curves have been used to determine dispersion coefficients and to determine how these coefficients vary as a function of solution velocity. This work is reported in another document. 18 
TABLE 16. COLUMN PARAMETERS FOR A TANR FARM SANDY

LOAM SOIL COLUMN

Parameter

Length

Soil Weight

Soil Volume

Flow Rate

Bulk Density

Temperature

$\mathrm{CaCO}_{3}$

$\mathrm{pH}$

Influent

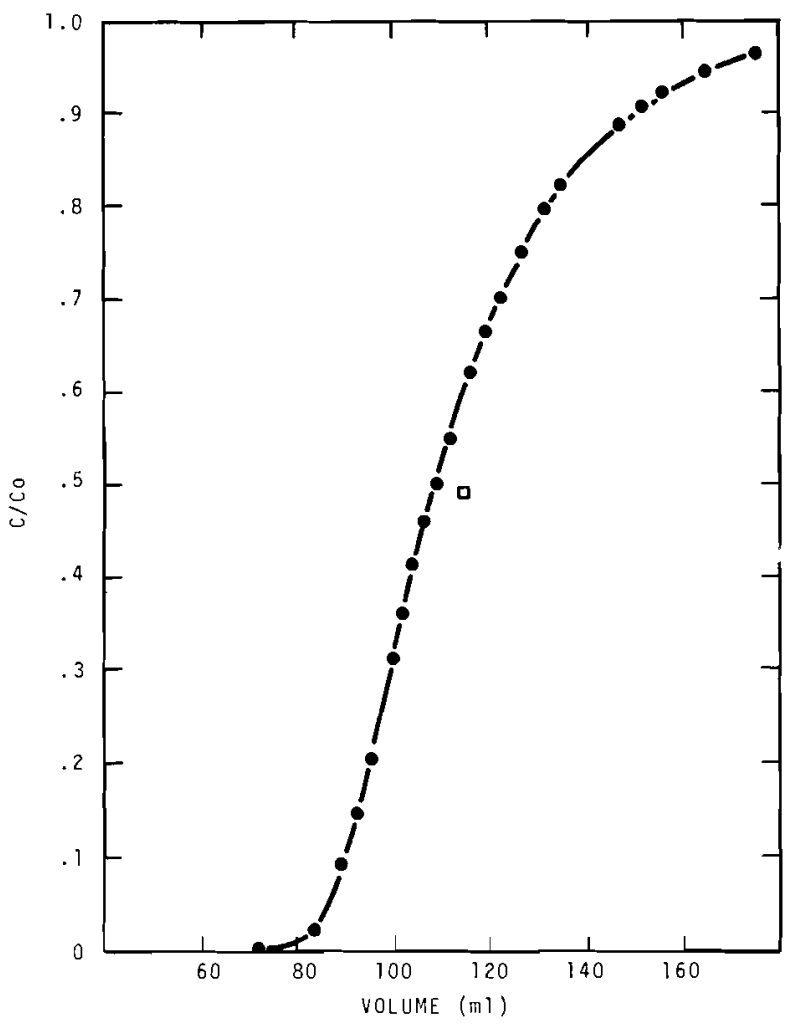

\section{Magnitude}

$27.3 \mathrm{~cm}$

466 gms

$294 \mathrm{~cm}^{3}$

$0.19 \mathrm{~cm} / \mathrm{hr}$

$1.59 \mathrm{gm} / \mathrm{cm}^{3}$

$23 \pm 3^{\circ} \mathrm{C}$

$2.6 \times 10^{-4}$. moles/gm

7.0

$0.078 \underline{\mathrm{M}} \mathrm{CaCl}_{2}$

FIGURE 3. Normalized Effluent Concentration (C/Co) of $\mathrm{Cl}$ from a $25 \mathrm{~cm}$ Tank Farm Sandy Loafy Soil Column as a Function of Effluent Solution Volume. Column was Preequilibrated with a $\mathrm{NO}_{3}$ Solution of the Same Cation Composition as the Tracer solution. Square ( D) Represents the Calculated $0.5 \mathrm{C} / \mathrm{Co}$ Volume Point. Flow Rate was 0.19 $\mathrm{cm} / \mathrm{hr}$. 


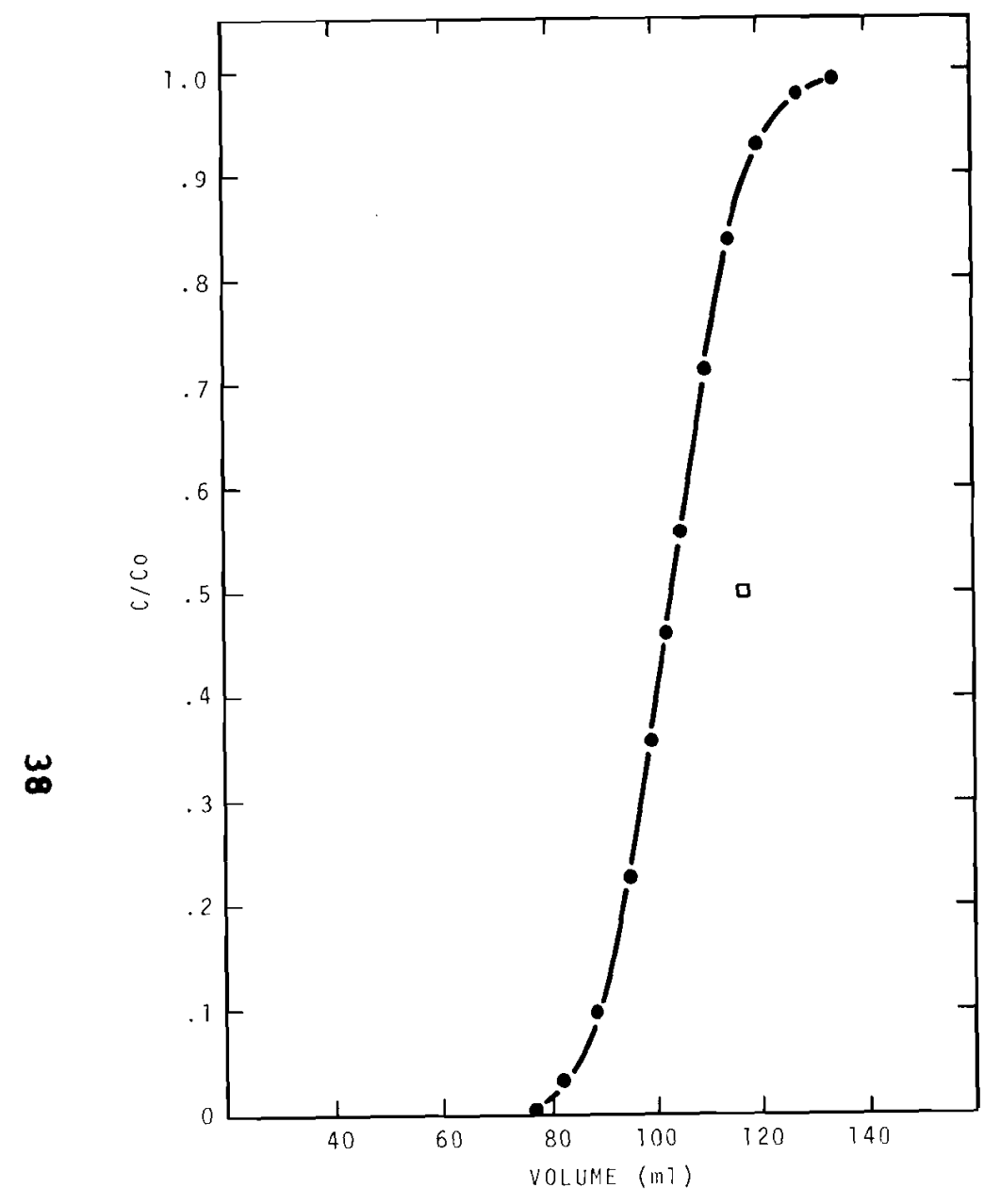

FIGURE 4. Normalized Effluent Concentration (C/Co) of $\mathrm{Cl}$ from a $25 \mathrm{~cm}$ Tank Farm Sandy Loam Soil Column as a Function of Effluent Solution Volume (flow rate was $0.50 \mathrm{~cm} / \mathrm{hr}$ ) *

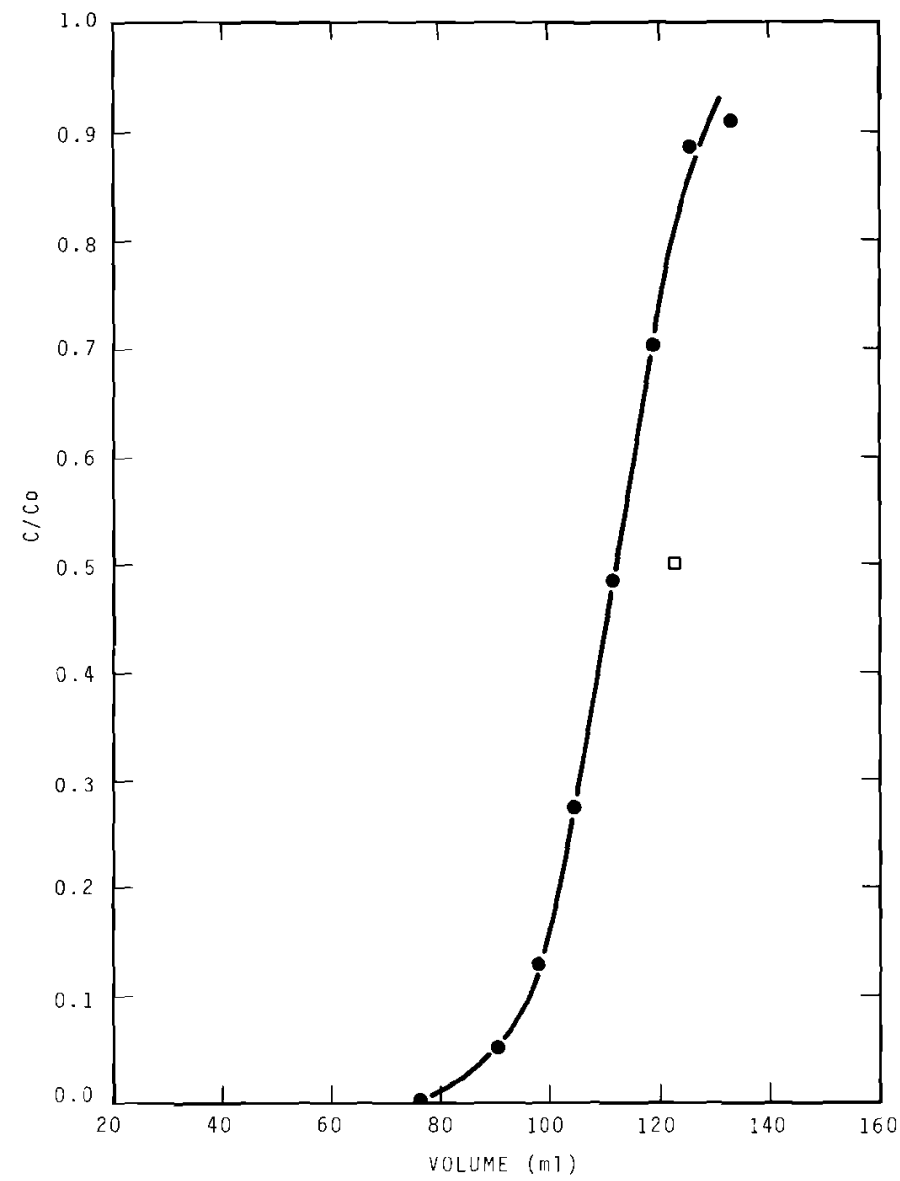

FIGURE 5. Normalized Effluent Concentration (C/Co) of ${ }^{3} \mathrm{H}$ from a $25 \mathrm{~cm}$ Tank Farm Sandy Loam Soil Column as a Function of Effluent Solution Volume (flow rate was $0.46 \mathrm{~cm} / \mathrm{hr}$ )*

* Column was Preequilibrated with a Nō Solution of Same Cation Composition as the Tracer Solution. Square ( $D$ ) Represents the Calculated $0.5 \mathrm{C} / \mathrm{Co}$ - Volume Point. 


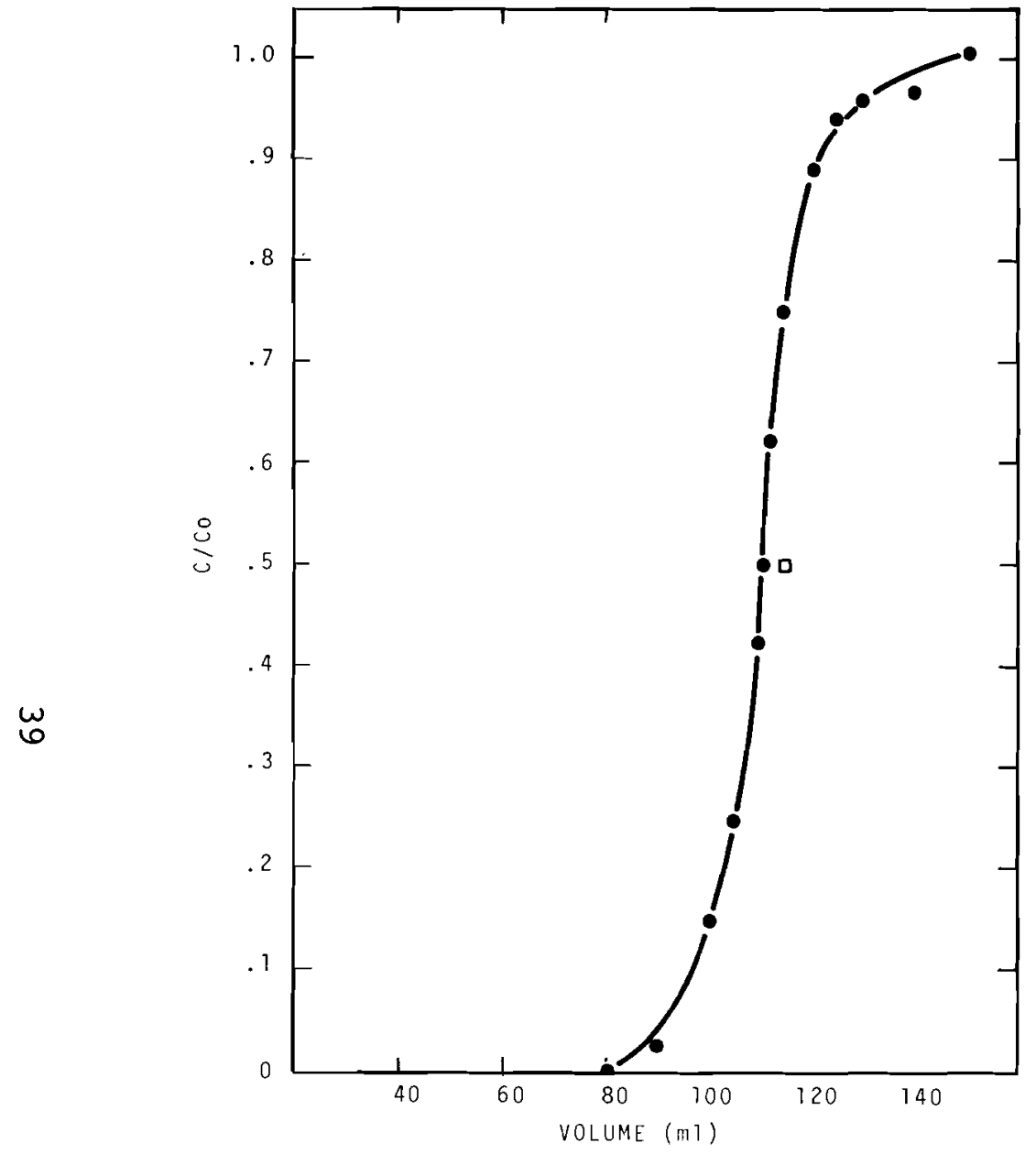

FIGURE 6. Normalized Effluent Concentration (C/Co) of $3 \mathrm{Cl}$ from a $25 \mathrm{~cm}$ Tank Farm Sandy Loam Soil Column as a Function of Effluent Solution

Volume (flow rate was $2.0 \mathrm{~cm} / \mathrm{hr}$ )*

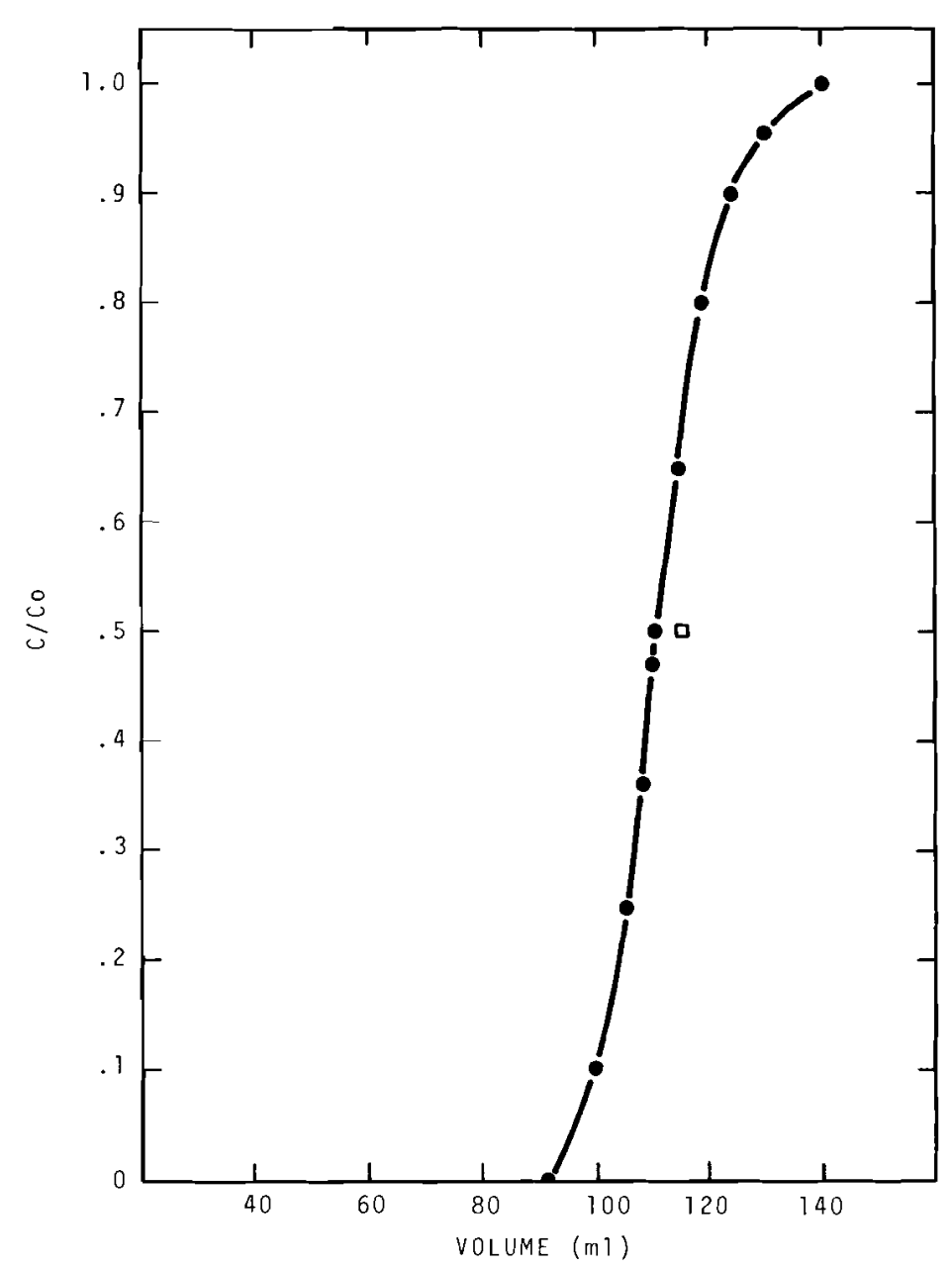

FIGURE 7. Normalized Effluent Concentration (C/Co) of Cl from a $25 \mathrm{~cm}$ Tank Farm Sandy Loam Soil Column as a Function of Effluent Solution

Volume (flow rate was $5.1 \mathrm{~cm} / \mathrm{hr}$ )*

*Column was Preequilibrated with a NO$\overline{3}$ Solution of the Same Cation Composition as the Tracer Solution. Square $(\square)$ Represents the Calculated $0.5 \mathrm{C} / \mathrm{Co}$ - Volume Point. 
Briefly the technique involves using an analytical solution to the one dimensional diffusion-convection equation. Measured values for the fluid velocity, column length and effluent breakthrough versus time and a trial and error procedure are then utilized to solve for $D$, the dispersion coefficient. Using the experimental data at several fluid velocities, the dispersion coefficient values for the different velocities were determined. The final form of the dispersion coefficient velocity relationship was found to be

$$
\mathrm{D}=\mathrm{aV}+\mathrm{b}
$$

where

$$
\begin{aligned}
D & =\text { dispersion coefficient }\left(\mathrm{cm}^{2} / \mathrm{min}\right) \\
V & =\text { fluld velocity, }(\mathrm{cm} / \mathrm{min}) \\
\mathrm{a}, \mathrm{b} & =\begin{array}{l}
\text { constants which are functions of the soil type } \\
\text { used }
\end{array}
\end{aligned}
$$

From the above experiments sufficient data was obtained to determine the value of the effective porosity and the velocity dependence of the dispersion coefficient. These results are used to correct the transport model to more closely represent the movement of solutes through a soil column. 


\section{ACKNOWLEDGMENTS}

This research was sponsored by the Advanced Technology Development Section, Research and Development Department, Atlantic Richfield Hanford Company. The authors are grateful for the assistance and direction provided by Dr. M. D. Veatch, Staff Hydrologist; D. J. Browin, Staff Geologist; and R. E. Isaacson, Manager of the Advanced Technology Development Section of Atlantic Richfield Hanford Company.

The efforts of Leila counts, who provided editorial assistance, and Jan Greenwell, Loretta Howard and Velva Harris, who typed the many drafts and final reports, are also greatly appreciated. 


\section{REFERENCES}

1. Routson, R. C. and R. J. Serne, "One Dimensional Model of the Movement of Trace Radioactive Solute Through Soil Columns: The PERCOL Model," BNWL-1718, 1972.

2. Baca, R. G., S. W. Ahlstrom, A. Brandstetter, R. J. Serne, and R. C. Routson, "Transport Model Theory and Numerical Implementation," BNWL-1715, 1974.

3. Serne, R. J., R. C. Routson, and D. A. Cochran, "Experimental Methods for Obtaining PERCOL Model Input and Verification Data," BNWL-1721, 1974.

4. Hajek, B. F., "Trace Strontium and Cesium Equilibrium Distribution Coefficients: Batch and Column Determinations," BNWL-SA-843, 1968 .

5. Ames, L. L. and B. F. Hajek, "Experimental Design for the Preliminary Study of Geochemical Process," BNWL-CC-573, 1966.

6. Routson, R. C., "A Review of Studies on Soil-Waste Relationships on the Hanford Reservation from 1944-1967," BNWL-1464, 1973.

7. Lewis, P. N. and M. Randall, Thermodynamics, 2nd Edition, Revised by K. S. Pitzer and L. Brewer, McGraw-Hill, 1961, pp. 343-348.

8. Harned, H. S. and B. B. Owen, "The Physical Chemistry of Electrolytic Solutions," 1958, pp. 731-732.

9. Butler, J. N., P. T. Hsu and J. C. Synnott, "Activity Coefficient Measurements in Aqueous Sodium Chloride Sodium Sulfate Electrolytes Using Sodium Amalgam Electrodes," The Journal of Physical Chemistry, Vol. 71, No. 4, 1967, pp. 910-913.

10. Butler, J. N. and R. Huston, "Activity Coefficient in Aqueous $\mathrm{NaCl}-\mathrm{CaCl}_{2}$ and $\mathrm{NaCl}-\mathrm{MgCl}_{2}$ Electrolytes Using Sodium Amalgam Electrodes," The Journal of Physical Chemistry, Vol. 71, No. 13, 1967, pp. 4479-4485.

11. Synnott, J. C. and J. N. Butler, "The Mean Activity Coefficient of Sodium Sulfate in Aqueous Sodium SulfateSodium Chloride Electrolytes," The Journal of Physical Chemistry, Vol. 72, No. 7, 1968, pp. 2474-2477. 
12. Huston, R. and J. N. Butler, "Calcium Activity Measurements Using a Liquid Ion Exchange Electrode in Concentrated Aqueous Solutions," Analytical Chemistry, Vol. 41, No. 1, 1969, pp. 200-202.

13. Shatkay, A., "Activity Coefficients of Calcium Ions in Mixed Solutions," The Journal of Physical Chemistry, Vol. 71, No. 12, 1967, pp. 3858-3861.

14. Gardner, A. W. and E. Glueckauf, "Ionic Association in Aqueous Solutions of Bivalent Sulphates," Proc. Roy. Soc. A., Vol. 13, 1969, pp. 131-147.

15. Gardner, A. W. and E. Glueckauf, "The Activity Coefficients of Electrolytes with Particular Reference to Aqueous Mixtures of 2:2 with 1:1 Electrolytes," Proc. Roy. Soc. A., Vol. 321, 1971, pp. 515-543.

16. Eliason, J. R., "Earth Sciences Waste Disposal Investigations January to June 1967," BNWL-687, 1967, p. 11 .

17. Reeve, R. C., "Air to Water Permeability Ratio," in C. A. Black, et al., Ed., Methods of Soil Analysis, Number 9 in the series Agronomy. Amer. Soc. Agron., Inc., Madison, WI, pp. 520-531.

18. Ahlstrom, S. W., R. J. Serne, R. C. Routson and D. B. Cearlock, "Methods for Estimating Transport Model Parameters for Regional Groundwater Systems," BNWL-1717, December 1974 .

19. Rose, D. A., "Some Aspects of the Hydrodynamic Dispersion of Solutes in Porous Materials," Journal of Soil Sci., 24 : 284-295, 1973 .

20. Nielsen, D. R. and J. W. Biggar, "Radioisotopes and Labeled Salts in Soil-Water Movement," Soil Moisture and Irrigation Studies, International Atomic Energy Agency, 1967, pp. 61-76. 
APPENDIX A

KASr AND PERMEABILITY FOR SATURATED ZONES OF SELECTED WELLS 
TABLE A-1. KdSr AND PERMEABILITY FOR THE SATURATED ZONE OF WELL 32-70

\begin{tabular}{|c|c|c|}
\hline $\begin{array}{l}\text { Depth } \\
\text { ft } \\
\end{array}$ & $\begin{array}{l}\mathrm{KdSr} \\
\mathrm{ml} / \mathrm{g}\end{array}$ & $\begin{array}{c}\text { Permeability } \\
\mathrm{cm} / \mathrm{min}\end{array}$ \\
\hline 250 & 6.0 & 0.014 \\
\hline 260 & 13.4 & 0.051 \\
\hline 265 & 14.0 & 0.063 \\
\hline 270 & 14.6 & 0.0058 \\
\hline 275 & 12.9 & 0.075 \\
\hline 280 & 18.6 & 0.075 \\
\hline 285 & 19.1 & 0.056 \\
\hline 290 & 18.9 & 0.039 \\
\hline 295 & 19.3 & 0.0038 \\
\hline 300 & 18.4 & 0.0041 \\
\hline 305 & 17.1 & 0.0078 \\
\hline 310 & 17.5 & 0.0067 \\
\hline 315 & 16.1 & 0.016 \\
\hline 320 & 18.5 & 0.0059 \\
\hline 325 & 16.2 & 0.027 \\
\hline 330 & 18.4 & 0.028 \\
\hline 340 & 14.2 & 0.011 \\
\hline 345 & 19.2 & 0.0051 \\
\hline 350 & 18.5 & 0.025 \\
\hline & 16.3 & 0.026 \\
\hline
\end{tabular}




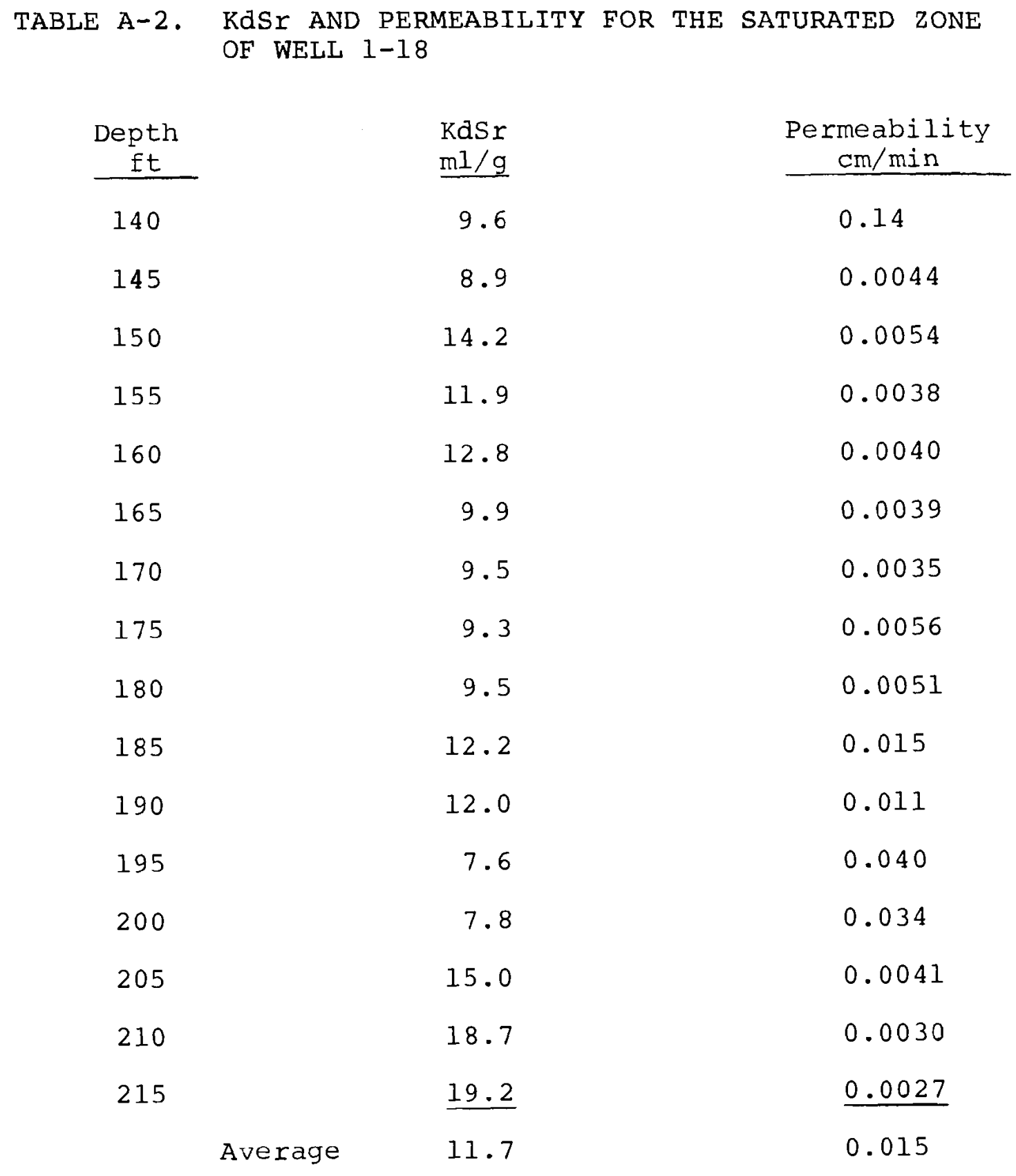


TABLE A-3. KdSr AND PERMEABILITY FOR THE SATURATED ZONE OF WELL $31-31 P$

\begin{tabular}{|c|c|c|}
\hline $\begin{array}{c}\text { Depth } \\
\text { ft } \\
\end{array}$ & $\begin{array}{l}\mathrm{KdSr} \\
\mathrm{ml} / \mathrm{g}\end{array}$ & $\begin{array}{c}\text { Permeability } \\
\mathrm{cm} / \mathrm{min}\end{array}$ \\
\hline 135 & 12.9 & 0.0474 \\
\hline 140 & 11.8 & 0.031 \\
\hline 145 & 13.1 & 0.010 \\
\hline 150 & 9.7 & 0.0057 \\
\hline 155 & 8.1 & 0.0036 \\
\hline 165 & 11.3 & 0.0031 \\
\hline 170 & 11.3 & 0.0042 \\
\hline 175 & 6.2 & 0.21 \\
\hline 180 & 8.5 & 0.096 \\
\hline 185 & 14.0 & 0.015 \\
\hline 190 & 7.0 & 0.27 \\
\hline 195 & 5.6 & 0.44 \\
\hline 200 & 8.4 & 0.10 \\
\hline 205 & 10.4 & 0.0073 \\
\hline 210 & -7.3 & 0.20 \\
\hline & 9.4 & 0.10 \\
\hline
\end{tabular}


TABLE A-4. KASr AND PERMEABILITY FOR THE SATURATED ZONE OF WELI 37-43P

\begin{tabular}{|c|c|c|}
\hline $\begin{array}{l}\text { Depth } \\
\mathrm{ft} \\
\end{array}$ & $\begin{array}{l}\mathrm{KdSr} \\
\mathrm{m} \mathrm{l} / \mathrm{g}\end{array}$ & $\begin{array}{c}\text { Permeability } \\
\mathrm{cm} / \mathrm{min}\end{array}$ \\
\hline 285 & 11.4 & 0.0075 \\
\hline 305 & 7.7 & 1.7 \\
\hline 315 & 9.2 & 0.058 \\
\hline 320 & 9.0 & 0.042 \\
\hline 325 & 9.0 & 0.061 \\
\hline 335 & 6.7 & 1.2 \\
\hline & 8.8 & 0.51 \\
\hline
\end{tabular}




\section{APPENDIX B}

COLUMN PARAMETERS FOR A TANK FARM SANDY LOAM SOIL COLUMN 
TABLE B-1. COLUMN PARAMETERS FOR A TANK FARM SANDY
LOAM SOIL COLUMN

$\underline{\text { Parameter }}$

Length

Soil Weight

Soil Volume

Flow Rate

Bulk Density

Temperature

Influent $\left(\mathrm{Ca}^{++}\right)$

Influent $\left(\mathrm{Na}^{+}\right)$

Influent $\left(\mathrm{K}^{+}\right)$

Influent $\left(\mathrm{Cl}^{-}\right)$
Magnitude

$24.5 \mathrm{~cm}$

$417.2 \mathrm{~g}$

$263 \mathrm{~cm}^{3}$

$0.50 \mathrm{~cm} / \mathrm{hr}$

$1.58 \mathrm{~g} / \mathrm{cm}^{3}$

$23^{\circ} \pm 3^{\circ} \mathrm{C}$

$0.002 \mathrm{M}$

$0.15 \mathrm{M}$

$0.01 \mathrm{M}$

$164 \mathrm{meq} / 1$

TABLE B-2. COLUMN PARAMETERS FOR A TANK FARM SANDY LOAM SOIL COLUMN

Parameter

Length

Soil Weight

Soil Volume

Flow Rate

Bulk Density

Temperature

Influent $\left(\mathrm{Ca}^{++}\right)$

Influent $\left(\mathrm{Na}^{+}\right)$

Influent $\left(\mathrm{K}^{+}\right)$

Influent ${ }^{3} \mathrm{H}$
Magnitude

$24.9 \mathrm{~cm}$

$428 \mathrm{~g}$

$268 \mathrm{~cm}^{3}$

$0.46 \mathrm{~cm} / \mathrm{hr}$

$1.60 \mathrm{~g} / \mathrm{cm}^{3}$

$23^{\circ} \pm 3^{\circ} \mathrm{C}$

$.002 \mathrm{M}$

$0.15 \mathrm{M}$

$0.01 \mathrm{M}$

$3.91 \mathrm{pci} / \mathrm{ml}$ 
TABLE B-3. COLUMN PARAMETERS FOR A TANK FARM SANDY
LOAM SOIL COLUMN

$\begin{array}{ll}\text { Parameter } & \frac{\text { Magnitude }}{27.3 \mathrm{~cm}} \\ \text { Length } & 466 \mathrm{gms} \\ \text { Soil Weight } & 294 \mathrm{~cm}^{3} \\ \text { Soil Volume } & 2.0 \mathrm{~cm} / \mathrm{hr} \\ \text { Flow Rate } & 1.59 \mathrm{gms} / \mathrm{cm}^{3} \\ \text { Bulk Density } & 23 \pm 3^{\circ} \mathrm{C}^{-4} \mathrm{moles} / \mathrm{gm}^{\text {Temperature }} \\ \text { CaCO } & 2.6 \mathrm{x}^{-4} \\ \text { pH } & 7.0 \\ \text { Influent } & 0.078 \mathrm{M} \mathrm{CaCl}\end{array}$

TABLE B-4. COLUMN PARAMETERS FOR A TANK FARM SANDY LOAM SOIL COLUMN

Parameter

Length

Soil Weight

Soil Volume

Flow Rate

Bulk Density

Temperature

$\mathrm{CaCO}_{3}$

$\mathrm{pH}$

Influent
Magnitude

$26.6 \mathrm{~cm}$

454 gms

$286 \mathrm{~cm}^{3}$

$5.1 \mathrm{~cm} / \mathrm{hr}$

$1.59 \mathrm{gms} / \mathrm{cm}^{3}$

$23 \pm 3^{\circ} \mathrm{C}$

$2.6 \times 10^{-4} \mathrm{moles} / \mathrm{gm}$

7.0

$0.074 \mathrm{M} \mathrm{CaCl}_{2}$ 


\section{DISTRIBUTION}

No. of

Copies

Off-Site

AEC Chicago Patent Group

G. H. Lee

$\underline{\text { AEC Technical Information Center }}$

Atomic Energy Commission Headquarters Waste Management and Transportation Germantown, Maryland 20767

Owen P. Gornley

Chief, Waste Facilities Branch

Robert W. Ramsey, Jr.

Chief, Development Branch

Atomic Energy Commission Site Safety Division Directorate of Regulation 7920 Norfolk Avenue

Bethesda, Maryland 20014

Ronald L. Bullard

Chief, Environmental Specialist Branch

W. Gamill

Chief, Site Analysis Branch

Atomic Energy Commission

Division of Production \& Material Management Washington, D. C. 20545

William L. Lennemann Chief, Chemical Process

James W. Pollock

Atomic Energy Commission

Idaho Falls, Idaho 83401

Dr. Adrian H. Dahl

Chief, Environmental Science Branch

B. I. Schmalz 
No. of

Copies

Off-Site

3

U. S. Geological Survey

2100 M. Street

Washington, D. C. 20037

George Debuchananne, Director

M. K. Hubbert

Research Geophysicist

Dallas Peck

1

U. S. Geological Survey

Menlo Park, California 94025

Jacob Rubin

1

U. S. Geological Survey

Groundwater Branch

Denver, Colorado

R. W. Stallman

U. S. Geological Survey

Water Resources Division

Bldg. 53, Room H-2910

Lakewood, Color ado 80225

J. D. Bredehoeft

1

U. S. Geological Survey

Water Resources Division

P.O. Box 917

Council Bluffs, Iowa 51501

O. J. Ramsvick

Supervisory Hydrologist

1

U. S. Geological Survey

Albuquerque, New Mexico

Dr. C. V. Theis

1

U. S. Geological Survey

Water Resources Division

P.O. Box 2857

Raleigh, North Carolina

Ralph C. Heath

District Chief

Distr-2 


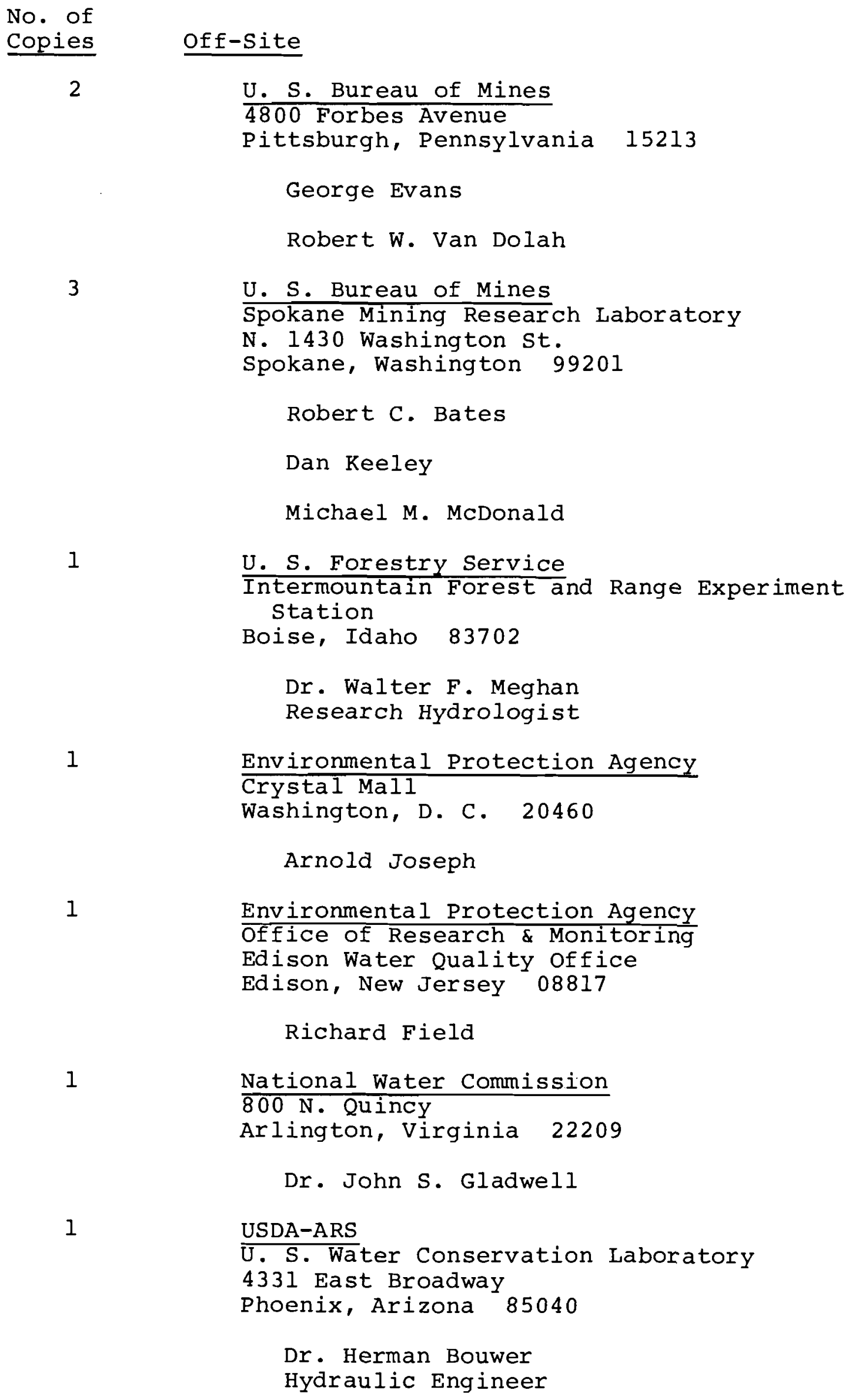

U. S. Bureau of Mines 4800 Forbes Avenue

U. S. Bureau of Mines Spokane Mining Research Laboratory N. 1430 Washington st. Spokane, Washington 99201

Robert C. Bates

Dan Keeley

Michael M. McDonald

U. S. Forestry Service

Intermountain Forest and Range Experiment Station Boise, Idaho 83702

Dr. Walter F. Meghan

Research Hydrologist

Environmental Protection Agency Crystal Mal1 Washington, D. C. 20460

Arnold Joseph

1

Environmental Protection Agency Office of Research \& Monitoring Edison water Quality office

Edison, New Jersey 08817

Richard Field

National Water Commission 800 N. Quincy Arlington, Virginia 22209

Dr. John S. Gladwell 4331 East Broadway Phoenix, Arizona 85040

Dr. Herman Bouwer Hydraulic Engineer 
No. of

Copies

Off-Site

1

USDA-ARS

U. S. Salinity Laboratory

P.O. Box 672

Riverside, California 92502

Dr. Jan Van Schilfgaarde, Director

1

USDA-ARS

Engineering Research Center CSU Foothills Campus

Fort Collis, Colorado 80521

Dr. David A. Woolhiser

Hydraulic Engineer

1

USDA-ARS

Northwest Watershed Research Center

P.O. Box 2700

Boise, Idaho 83701

Walter J. Rawls, Hydrologist

1

USDA-ARS

P.O. BOX 1096

Boise, Idaho 83701

J. L. Robins

1

USDA-ARS

Twin Falls, Idaho

M. E. Jensen

1

USDA-ARS

Snake River Conservation Research Center Route 1, Box 186

Kimberly, Idaho 83341

Dr. Marvin E. Jensen, Director

1

USDA Hydrograph Laboratory

Plant Industry Station

Soils Building

Beltsville, Maryland 20705

H. N. Holton, Director

1

USDA-ARS

Plant Industry station

Beltsville, Maryland 20705 
No. of

Copies off-site

Dr. Donald L. Brakensick

Chief Engineer

1

USDA Sedimentation Laboratory

P.O. BOX 30

Oxford, Mississippi 38655

A. R. Robinson, Director

1

USDA-ARS

Southern Region

Stoneville, Mississippi 38776

John C. Stephens, Director

1

USDA-ARS

North Central Watershed Research Center P.O. Box 916

Columbia, Missouri 65201

Dr. C. R. Amerman

Hydraulic Engineer

1

USDA-ARS

North Appalachian Experimental Watershed Coshocton, ohio 43812

Dr. W. M. Edwards

Soil Scientist

1

USDA

P.O. Box 400

Chickasha, Oklahoma 73018

Harry B. Pionke

1

USDA-ARS

Northeast watershed Research Center Pennsylvania State University

111 Research Building 3

University Park, Pennsylvania 16802

Dr. A. S. Rogowski

Soil Scientist

National Academy of Science U. S. National Committee for the IHD 2101 Constitution Avenue Washington, D. C. 20418

Dr. Leo Heindl

Executive Secretary 
No. of

Copies

Off-Site

1

National Academy of Science

Committee on Radioactive Waste Management National Research Council

2101 Constitution Avenue

Washington, D. C. 20418

Dr. Cyrus Klingsberg

Technical Secretary

1

National Science Foundation

Division of Advanced Technology Application 18006 th Street N.W.

Washington, D. C. 20530

Ray Zahradnik

1

U. S. Naval Civil Engineering Laboratory

Port Hueneme, California 93043

Dr. James J. Der

2

Robert S. Kerr Water Research Center

P.O. BOX 1198

Ada, Oklahoma 74820

Dr. J. W. Keeley

Marion R. Scalf

1

Alabama Geologic Survey

P.O. Drawer O

University, Alabama 35486

Phil Lammereaux

State Geologist

1

Southwest Rangeland Watershed Research

Center

442 E. Seventh Street

Tucson, Arizona 85705

Dr. R. Smith

1

California Dept. of Water Resources Sacramento, California

Helen J. Peters

Distr -6 
No. of

Idaho Bureau of Mines \& Geology University of Idaho Moscow, Idaho 83843

Dr. Roy E. Williams

1

Idaho Dept. of Water Administration

State House, Annex 2

Boise, Idaho 83707

Keith R. Higginson, Director

Idaho Water Resources Board

Boise, Idaho

R. R. Lee

1

Illinois state Water Survey P.O. Box 232

Urbana, Illinois 61801

Keros Cartwright

1

State Geological Survey of Kansas

University of Kansas

Lawrence, Kansas 66044

Dr. John C. Ha lepaska

Chief, Water Resources Section

1

State of Maine

Environmental Improvement Commission Augusta, Maine 04330

Steven D. Freedman

1

St. Anthony Falls Hydraulic Laboratory Mississippi River at 3rd Avenue East Minneapolis, Minnesota 55414

Professor C. Edward Bowers

2

Desert Research Institute

Center for water Resources Research

Reno, Nevada

Dr. Clinton Case

G. B. Maxey 


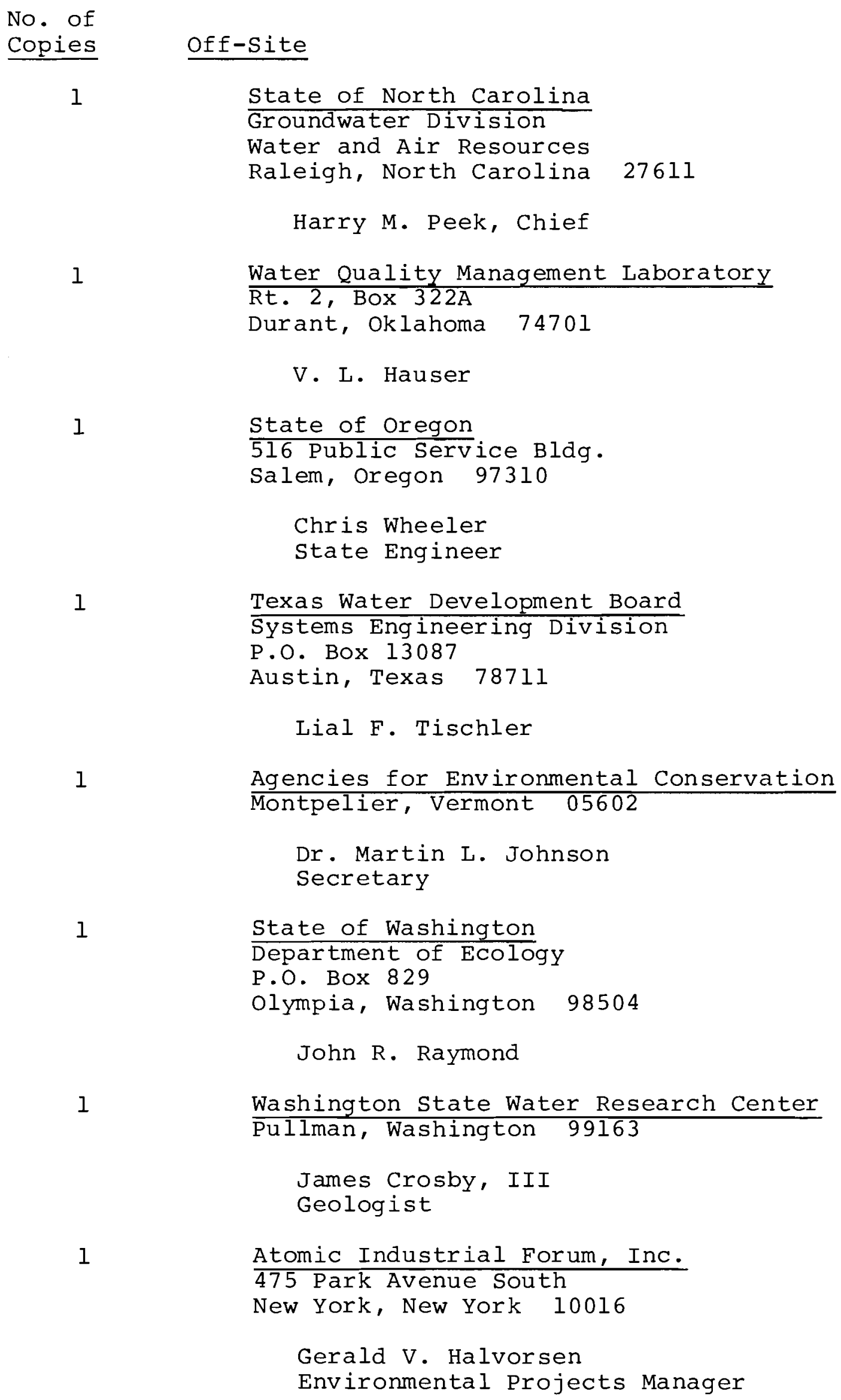

State of North Carolina Groundwater Division Water and Air Resources Raleigh, North Carolina 27611

State of Washington

Department of Ecology

Atomic Industrial Forum, Inc.

475 Park Avenue South

New York, New York 10016

Gerald V. Halvorsen

Environmental Projects Manager 
No. of

Copies

1

1

1

1

1

1

1

2
Off-site

Computer Sciences Corp.

Federal Building

Richland, Washington 99352

R. W. Nelson

Sandia Laboratories

Division 5166

Albuquerque, New Mexico 87115

Fred Norwood

Arthur M. Piper

\#3 Sonoma Lane

Carmel, California 93921

Alyeska Pipeline Service Co.

2100 Travis Street

Houston, Texas 77002

Dr. Maurice D. Veatch

E. I. duPont deNemours \& Co., Inc. Savannah River, South Carolina

$$
\text { J. C. Corey }
$$

University of Arizona

Office of Arid Lands Studies

1201 East Speedway Blvd.

Tucson, Arizona 95719

Dr. Ken Faster

University of Arizona

Dept. of Agriculture Chemistry and Soils Tucson, Arizona 85721

Dr. Gordon Dutt

University of Arizona

Dept. of Hydrology and water Resources

200-E old Psychology

Tucson, Arizona 95721

Dr. A. K. Tyagi

Dr. Chester C. Kisiel 
E. S. Simpson

A. W. Warrick

University of California

Berkeley, California 94720

Dr. Warren Kauffman

P. A. Witherspoon

Dept. of Civil Engineering

3

University of California at Davis

Dept. of Water Sciences and Engineering Davis, California 95616

J. N. Luthin

Don Nielson

Dr. Verne H. Scott

1

University of California at Riverside College of Biological \& Agricultural Sciences

Riverside, California 92507

Dr. N. T. Coleman

Stanford University Department of Civil Engineering Stanford, California 94305

Paul Kruger

Henry J. Ramey

J. B. Franzini

Stanford University School of Earth Sciences Dept. of Geology Stanford, California 94305

E. Aguado 
No. of Copies Off-Site

1

Georgia Institute of Technology

School of Civil Engineering

Atlanta, Georgia 30332

Dr. J. R. Wallace

1

University of Idaho

Moscow, Idaho 83843

Dr. Delbert Fitzsimmons

Head, Agricultural Engineering

2

University of Illinois Urbana, IIlinois 61801

A. Klute

Professor Ven Te Chow

Hydrosystems Laboratories

1

Purdue University

Dept. of Agricultural Engineering

wast LaFayette, Indiana 47907

Emru D. Millette

1

Iowa state University

Ames, Iowa

D. Kirkham

1

University of Kansas

Water Resources Institute Lawrence, Kansas 66044

Don W. Green

University of Kentucky

Department of Mechanical Engineering Lexington, Kentucky 40506

C. T. Hahn

1

Harvard University

School of Public Health

Boston, Massachusetts 02138

Dr. D. W. Moeller

Distr-11 
No. of

Copies

Off-Site

1

Massachusetts Institute of Technology 77 Massachusetts Avenue Room 48-263

Cambridge, Massachusetts 02139

Dr. Donald Harleman

1

University of Minnesota Department of Geology and Geophysics 2D Pillsbury Hall

Minneapolis, Minnesota 55455

Hans Olaf Pfannkuch

1

University of Minnesota Department of Civil Engineering Minneapolis, Minnesota 55418

H. Steforn

2

University of Nebraska School of Civil Engineering

Lincoln, Nebraska 68503

Mark J. Hammer

Warren Viessman, Jr.

1

Princeton University

School of Engineering/Applied Science

Department of Civil and Geological

Engineering

Princeton, New Jersey 08540

Dr. Robert W. Cleary

2

Princeton University

Department of Civil \& Geological

Engineering

Princeton, New Jersey 08540

R. J. M. DeWiest

G. F. Pinder

1

New Mexico State University

Department of Agronomy

P.O. Box 3Q

Las Cruces, New Mexico 88001

P. J. Wierenga 
No. of

Copies

1

1

2

2

1

1

1
Off-site

State University of New York at Buffalo

Dept. of Mechanical Engineering

Buffalo, New York 14214

Ralph T. Cheng

State University of New York

Dept. of Civil Engineering

Buffalo, New York 14214

Dr. Ralph Rumer

Cornell University

School of Civil Engineering

B22 Bailey Hall

Ithaca, New York 14850

W. H. Brutsaert

Winton Covey

Oregon State University Corvallis, Oregon 97331

Dr. Larry Boersma

Professor of Soils

Dr. Royal H. Brooks

Professor of Agricultural Engineering

Drexel Institute of Technology

Philadelphia, Pennsylvania 19104

Irwin Remson

Vanderbilt University

Nashville, Tennessee 37203

Dr. Frank L. Parker

Utah State University

College of Engineering

Dept. of Agriculture and Irrigation

Engineering

Logan, Utah 84321

Dr. L. G. King 
No. of

Copies Off-Site

1

Utah State University

Utah water Research Laboratory

College of Engineering

Logan, Utah 84321

J. Paul Riley

1

Utah State University

Logan, Utah 84321

Dr. Roland $W$. Jeppson

Associate Prof. of Civil Engineering

1

Utah State University

Logan, Utah 84321

C. G. Clyde

1

University of Wyoming

Laramie, Wyoming 82070

Dr. Paul A. Rechard

Director, Water Resources Research Institute

2

Washington State University

Dept. of Civil Engineering

148 Sloan $\mathrm{Hall}$

Pullman, washington 99163

Dr. Donald L. Bender

Dr. David Higgins

2

Washington State University

Dept. of Agronomy \& Soils

Pullman, washington 99163

Dr. Walter H. Gardner

Dr. Eugene Thompson

1

Washington State University

Albrook Hydraulic Laboratory

Pullman, Washington 99163

Dr. John F. Orsborn, Head 
No. of

Copies

Off-Site

1

University of Washington

Department of Geology

Seattle, washington 98105

Dr. Howard Coombs

2

University of Wisconsin Department of Soil Science

Madison, Wisconsin 53706

W. R. Gardner

P. Saffigna

1

Water Conservation and Irrigation Commission

P.O. Box 20R Royal Exchange

Sydney, 2000, Australia

Frans R. Kalf

1

University of New South Wales

School of Civil Engineering

Sydney, Australia

Dr. K. K. Watson

1

Institut für Geophysik

Technische Hochschule

Karlsplatz 13

A-1040 WIEN Österreich

Austria

A. E. Scheidegger

1

University of British Columbia Vancouver, B. C., Canada

Dr. Allen Freeze

1

Dept. of Mines and Natural Resources Water Resources Branch

693 Taylor Avenue

Winnipeg 9, Manitoba, Canada

Frank W. Render 
No. of

Copies

Off-site

1

University of waterloo

Department of Earth Science

Waterloo, ontario, Canada

Richard G. Jackson

1

University of Waterloo

Department of Civil Engineering

Faculty of Engineering

Waterloo, Ontario, Canada

John F. Pickens

1

McMaster University

Department of Civil Engineering

Hamilton, Ontario, Canada

Dr. William James

2

Ontario Water Resources Commission

135 st. Clair Avenue West

Toronto 7, Ontario, Canada

Donald N. Jeffs

Bob Ostry

1

Department of the Environment

4905 Dufferin street

Downsview, Ontario, Canada

Dr. Aloysius K. Lo

2

Department of the Environment

C-244, No. 8 Temporary Bldg.

Inland Waters Branch

Ottawa, Canada

R. E. Jackson

Dennis Lawson

1

Institut de Mecanique (I.M.G.) Domaine Universitaire

B. P. 53

Centre de Tri 38041

Grenoble-Cedex, France

Georges Vachaud 


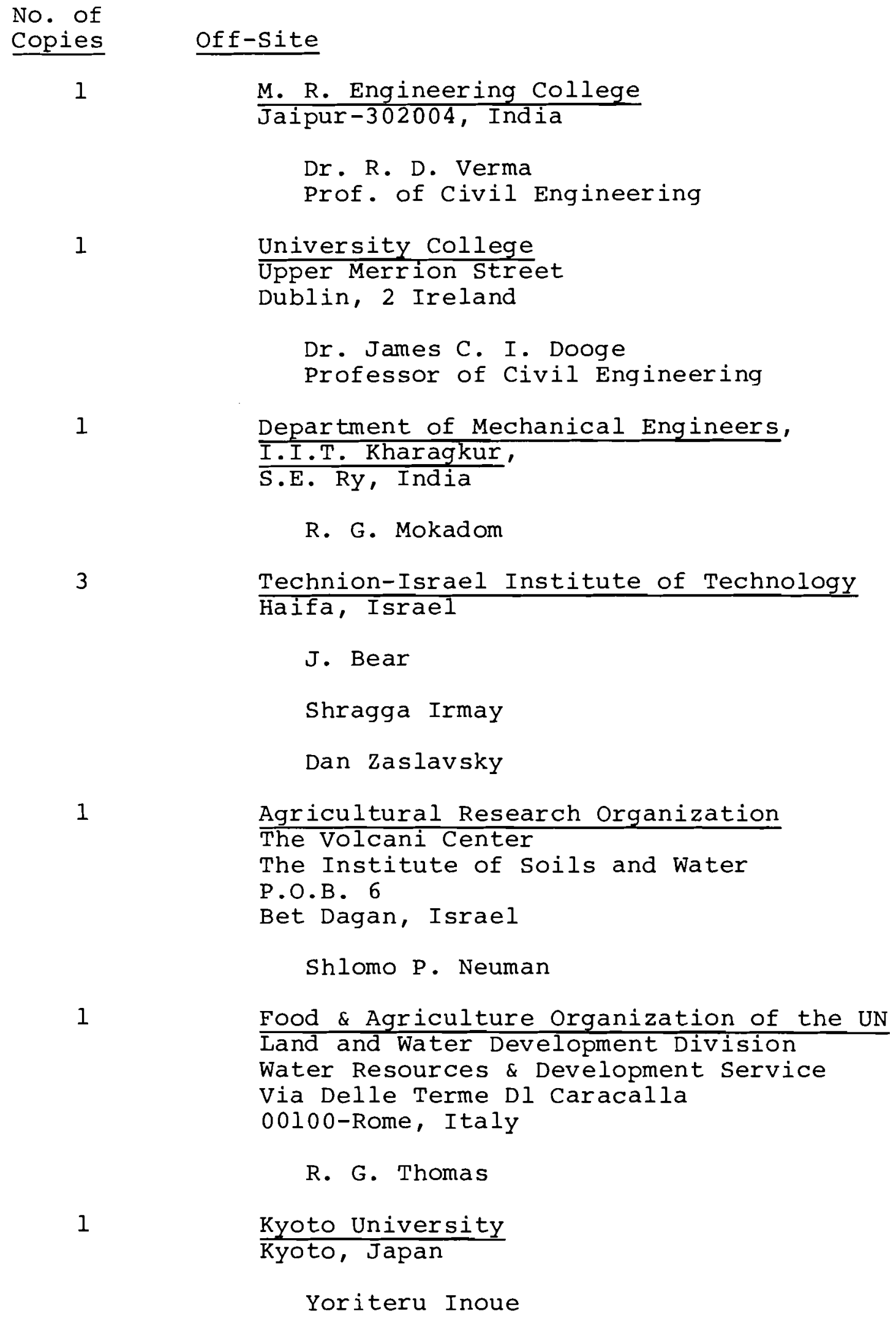

Department of Mechanical Engineers, I.I.T. Kharagkur,

S.E. RY, India

R. G. Mokadom

Technion-Israel Institute of Technology Haifa, Israel
J. Bear
Shragga Irmay
Dan Zaslavsky

Agricultural Research Organization The Volcani Center

The Institute of Soils and water P.O.B. 6

Bet Dagan, Israel

Shlomo P. Neuman

Food \& Agriculture Organization of the UN Land and Water Development Division Water Resources \& Development Service Via Delle Terme Dl Caracalla 00100-Rome, Italy

R. G. Thomas

$\frac{\text { Kyoto University }}{\text { Kyoto, Japan }}$

Yoriteru Inoue 
No. of

Copies

1

69

1

\section{Off-Site}

Explorade En Produktie Laboratorium c/o Koninklijke/Shell

Volmerlaan 6

Ritswijk (Z.H.), The Netherlands

A. M. Schaaps

University of Canterbury, N.Z. Dept. of Civil Engineering Christ Church 1 , New Zealand

Bruce W. Hunt

On-Site Hanford

AEC/RI Patent Attorney

R. M. Poteat

AEC Richland Operations office

O. J. Elgert

J. I. Rhoades

P. J. Holsted

E. B. Jackson

P. G. Rhoades

R. B. Goranson

B. J. Melton

Atlantic Richfield Hanford Co.

G. E. Backman

G. L. Borsheim

D. J. Brown

L. E. Bruns

M. H. Campbell

W. M. Harty

R. E. Isaacson

L. M. Knights

C. W. Malody

B. J. McMurray

M. C. Metz

H. P. Shaw

A. E. Smith

P. W. Smith

W. J. Van Slyke

ARHCO File

G. A. Nicholson 
No. of

Copies

On-Site Hanford

Westinghouse Hanford Co. HEDL

R. B. Hall

29

Battelle-Northwest

D. B. Cearlock

J. P. Corley

J. R. Eliason

K. L. Kipp

D. E. Olesen

A. E. Reisenauer

D. D. Tillson

R. C. Routson

R. J. Serne

D. R. Friedrichs

S. W. Ahlstrom

R. G. Baca

A. Brandstetter

R. D. Mudd

R. W. Wallace

J. J. Fuquay

A. J. Shuckrow

L. E. Addison

Tech. Information

Tech. Pubs.

United Nuclear, Inc.

C. D. Corbit

F. E. Owen 